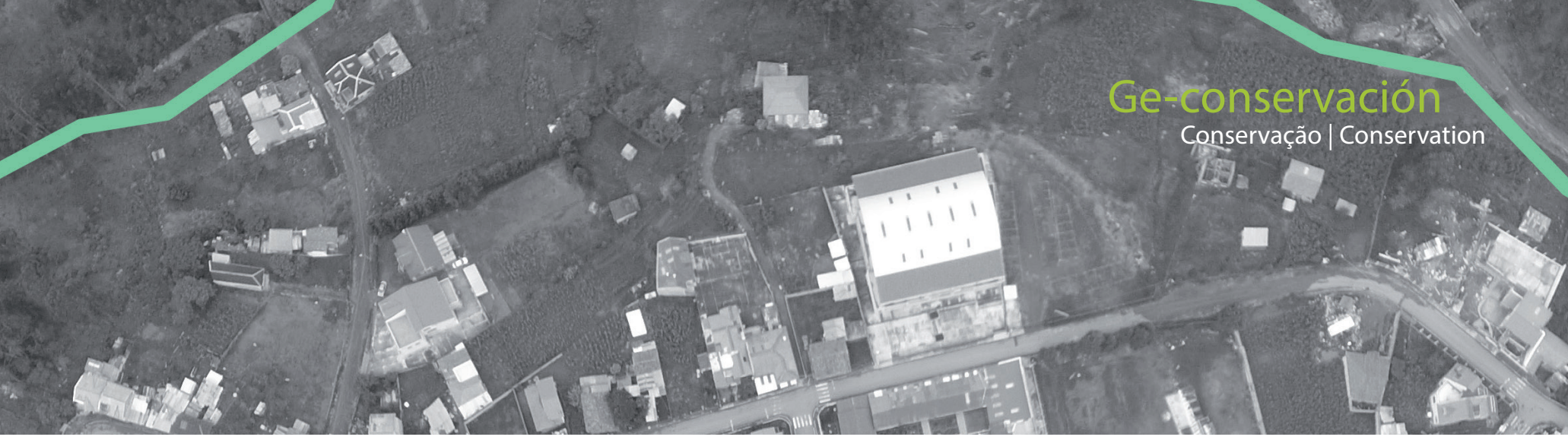

\title{
Morfotipología y estado de conservación en el patrimonio arquitectónico de Sinincay (Cuenca, Ecuador). Perspectivas hacia el desarrollo
}

\author{
Amanda Paulina García Cordero, María del Cisne Aguirre Ullauri
}

\begin{abstract}
Resumen: Cuenca (Ecuador) es una ciudad dispersa. Núcleos poblacionales como Sinincay se han desarrollado condicionados a factores socio-espaciales, políticos o económicos que han limitado la conservación patrimonial. La presente investigación describe el estado de conservación de la arquitectura patrimonial de dicho asentamiento para promoverla como estrategia de desarrollo. Se estudian 13 bienes inmuebles a partir del análisis morfotipológico, la aplicación de fichas urbano-arquitectónicas y herramientas ambientales. Como resultado se determinó que la tipología predominante es la continua en trama de carácter doméstico y que presentan estados de conservación regulares. Con estas condiciones, la aptitud como recurso de desarrollo enmarca al $31 \%$ de los bienes como parcialmente aptos, y a los restantes como aptos. Además, según la morfotipología, las variaciones en las expresiones formales posicionan el uso del portal como una invariante desde 1930, cuya alta capacidad de integración es propicia para la derivación de un plan piloto.
\end{abstract}

Palabras clave: arquitectura patrimonial, patrimonio periférico, morfotipología arquitectónica, conservación patrimonial, recurso de desarrollo

\section{Morphotypology and state of conservation in the architectural heritage of Sinincay (Cuenca, Ecuador). Perspectives towards development}

Abstract: Cuenca (Ecuador) is a dispersed city. Population nuclei such as Sinincay have developed conditioned by socio-spatial, political or economic factors that have limited heritage conservation. This research describes the state of conservation of the heritage architecture of this settlement in order to promote it as a development strategy. Thirteen properties were studied based on morphotypological analysis, the application of urban-architectural files and environmental tools. As a result, it was determined that the predominant typology is the continuous typology of domestic character and that they are in a regular state of conservation. With these conditions, the suitability as a development resource frames $31 \%$ of the properties as partially suitable, and the remaining ones as suitable. Furthermore, according to the morphotypology, the variations in the formal expressions position the use of the portal as an invariant since 1930, whose high capacity of integration is propitious for the derivation of a pilot plan.

Keywords: heritage architecture, peripheral heritage, architectural morpho-typology, heritage conservation, development resource

\section{Morfotipologia e estado de conservação no património arquitetónico de Sinincay (Cuenca, Equador). Perspetivas para o desenvolvimento}

Resumo: Cuenca (Equador) é uma cidade dispersa. Núcleos populacionais como Sinincay desenvolveram-se condicionados a fatores socio-espaciais, políticos ou económicos que limitaram a conservação patrimonial. A presente investigação descreve o estado de conservação da arquitetura patrimonial deste local para a promover como estratégia de desenvolvimento. São estudados 13 imóveis a partir da análise morfotipológica, a aplicação de fichas urbano-arquitetónicas e ferramentas ambientais. Como resultado, determinouse que a tipologia predominante é a contínua em trama de caráter doméstico e que apresentam estados de conservação regulares. Nestas condições, a aptidão como recurso de desenvolvimento enquadra $31 \%$ dos bens como parcialmente aptos e os restantes como aptos. Além disso, segundo a morfotipologia, as variações nas expressões formais posicionam o uso do portal como uma invariante desde 1930, cuja alta capacidade de integração é propícia para a derivação de um plano piloto.

Palavras-chave: arquitetura patrimonial, patrimônio periférico, morfotipologia arquitetónica, conservação patrimonial, recurso de desenvolvimento 


\section{Introducción}

La Revolución Industrial ocasionó el crecimiento acelerado de ciudades y con ello la transformación de la imagen urbano-arquitectónica a nivel mundial. Estos cambios significativos en los medios de producción que repercutieron en los procesos de urbanización tuvieron un gran impacto en América Latina. No obstante, la consolidación del sistema capitalista tardó casi un siglo en llegar al Ecuador, en donde, la influencia del mercado mundial creció hasta volverse irreversible en el proceso de urbanización del siglo XIX (Ayala Mora 2008: 27). Para el siglo XX, el crecimiento urbano se vinculó a factores económicos que propiciaron movimientos de migración rural-urbana (Carrión 1986: 71), lo que derivó en la implantación del modelo de ciudad dispersa en el país. Cuenca creció bajo ese contexto. Sus diversos núcleos de población como Ricaurte, El Valle, Baños y Sinincay se desarrollaron en el área periurbana como espacios segregados social y espacialmente, marcados por la inequidad y el desarrollo y condicionados por aspectos políticos y económicos.

Sin embargo, aunque una ciudad crezca seccionada, ciertos elementos (productos y manifestaciones) son capaces de mostrarse como vínculos entre la comunidad y el medio, a través de la apropiación social: los bienes patrimoniales. Estos representan diversos valores determinados por grupos o individuos, entre ellos el valor social, con la posibilidad de representar un nexo capaz de fortalecer la identidad comunitaria (Turbay Varona, Ortiz, Arana y Ortiz 2020: 267). Aun así, su continuidad se ve condicionada por factores socio-espaciales, políticos y económicos, de ahí la relevancia de reconocer y diferenciar estos territorios, sus recursos y necesidades específicas. En Cuenca, el patrimonio cultural de la periferia recibe tratamiento diferente al del patrimonio monumental reconocido y hasta convencional y se convierte en un área vulnerable al deterioro y pérdida. Para proteger esas manifestaciones tangibles e intangibles (Mejía 2014: 16), es necesario adoptar medidas de emergencia en función del desarrollo del territorio, lo que incluye considerar las características del patrimonio como un posible mecanismo para tal fin.

En el caso concreto de la parroquia Sinincay, se reconocen problemas tales como el desinterés cultural, el descuido de los espacios recreativos y la presencia de proyectos culturales sin correspondencia con la demanda de la población. También se observan potencialidades que podrían llevar a que el asentimiento se convierta en escenario óptimo para proponer alternativas de intervención, entre ellas destacan la arquitectura patrimonial, el paisaje y la diversidad productiva. Ental sentido, bien se pueden proponeropciones que superen la noción de las meticulosas operaciones intervencionistas, que responden a las necesidades de la sociedad posmoderna.

En este contexto, el presente trabajo de investigación tiene como fin comprender las formas y las características del patrimonio arquitectónico periférico de Sinincay con el afán de potenciarlo como recurso de bienestar emocional y productivo, es decir, como recurso de desarrollo. Se estudian trece bienes inmuebles del sitio inventariados por el Instituto Nacional de Patrimonio Cultural (INPC), se definen los tipos arquitectónicos mediante el análisis de sus características histórico constructivas, estructuras de forma y estado actual en el territorio, también se valoran los factores ambientales incidentes y las técnicas de intervención como posibles factores de riesgo y vulnerabilidad. Con estos insumos, se proponen alternativas de intervención para promover estrategias para el desarrollo.

\section{Antecedentes}

A nivel integral, el patrimonio vernáculo representa una construcción socio cultural compleja, de enorme significancia social para los distintos pueblos, por ser un producto que expresa la diversidad e identidad que los caracteriza. Ciertamente, al hablar de una comunidad en particular y del modo natural y tradicional en que se ha construido su hábitat, también se describe dicho patrimonio. Los bienes patrimoniales, ya sean inmuebles o en su más amplia diversidad (tangibles e intangibles), no se restringen a rastros palpables del pasado tales como monumentos arquitectónicos, obras de arte u otros, sino que también abarcan conocimientos, costumbres, formas de expresión, prácticas y hábitos sociales (Bonfil Batalla 2004: 118). Los bienes inmuebles, entonces, pueden considerarse fenómenos culturales que dependen de factores sociales, de los espacios en los que se insertan, de las condiciones físicas y de la actitud e ideales de las personas, capaces de generar conceptos que derivan en el sentimiento de reconocimiento (Rapoport 1965: 15).

La identificación y la valoración del patrimonio vernáculo se remonta a inicios del siglo XIX (García, Tamayo, Cobo y Coronel 2017), no obstante y pese a los esfuerzos por su estudio y conservación, las prácticas se ven obstaculizadas por la homogeneización cultural, arquitectónica y socio económica, lo que ocasiona que los bienes se vuelvan vulnerables y caigan en obsolescencia (ICOMOS 1999: 1). Esta carencia de mantenimiento y documentación técnica, apropiación, reconocimiento social, sumada a los cambios urbano-arquitectónicos y sociales, ha generado un sucesivo estado crítico de degradación que afecta directamente a su salvaguardia (Amaya 2006: 49-52). Frente a esta desvaloración del patrimonio, en 1967 los gobiernos demandaron la adopción de medidas de emergencia y la implementación de un plan sistemático de revalorización de bienes patrimoniales tendiente también al desarrollo económico-social de las sociedades (ICOMOS 1967:1). Desde entonces, las iniciativas a nivel mundial se multiplicaron.

\section{a) El contexto entre el caso ecuatoriano y el cuencano}

En el Ecuador varios procesos de cambio a nivel urbano estuvieron ligados a la transformación económica, social 
y tecnológica ocurrida en el Viejo Continente gracias a la apertura del canal de Panamá (1914). Algunos núcleos urbanos comenzaron a despuntar comercial y financieramente debido a la exportación de cultivos (Carrión 1986: 38). Por su parte, Cuenca progresivamente se fue convirtiendo en un modelo disperso, lo que generó un impacto en la sociedad: aumentó la inequidad social, se perdió el sentido de la comunidad y del espacio público y aumentó la desigualdad en el acceso a servicios. A día de hoy, estos problemas generan segregación y determinan una configuración particular de su núcleo urbano favorecido (Hermida, Hermida, Cabrera y Calle 2015: 27).

Frente a estos problemas, es importante considerar a los elementos y bienes de carácter patrimonial como vehículos capaces de vincular a la comunidad con su medio. De esta manera, se podría retomar el interés por el centro de la ciudad y generar mayor cohesión social y espacial. Pese a ello, existe una visión y comprensión diversa y distante sobre el patrimonio convencional y el periférico. En el caso concreto de la arquitectura en la periferia, según Gámez (2008), se evidencia un proceso de configuración y valoración de la cultura material e intangible particular y se crea un espacio social con diversos grados de aceptación o conflicto, plenamente aplicable al caso cuencano y ecuatoriano. Así, el tratamiento que reciben los bienes en el área periurbana y rural de Cuenca responde a un criterio empírico o nulo en ciertos casos, lo que dificulta aún más su conservación.

En el ámbito cultural en Ecuador no siempre se ha contado con el mejor escenario para valorar el patrimonio cultural y más bien ha primado un marco poco sostenido A comienzos del siglo XIX, por ejemplo, el historiador Federico González Suárez manifestaba que "el obsequio o venta de bienes patrimoniales que debían estar custodiados en museos se realizaba con gusto" (Kennedy Troya 2016: 238), lo que ocasionó la pérdida de objetos de gran valor. A mediados de ese siglo, la conciencia patrimonial apenas empezó a transformarse. En 1872 se instaló la Escuela de Bellas Artes en Quito, pero no logró concientizar en torno al cuidado de los bienes (Kennedy Troya 2016).

En el siglo XX emergieron ya propuestas más significativas. En 1944 se creó la Casa de la Cultura Ecuatoriana, y en 1945 se promulgó la Ley de Patrimonio Artístico, sustituida posteriormente por la Ley Nacional de Cultura. En 1973 se emitió la primera Ley de Cultura, bajo el mandato de Guillermo Rodríguez Lara, con el objetivo de fortalecer la gestión cultural desde la institucionalidad pública y de regular a organismos como la Casa de la Cultura y el Consejo Nacional de Cultura (Mejía 2014: 18). En 1978 se creó el INPC. Un año más tarde se instauró la Ley de Patrimonio Cultural que se encargaba de la gestión y protección de las edificaciones registradas (López Ulloa 2004: 60) y de brindar recomendaciones generales para intervenciones basadas en los criterios expuestos en la
Carta Internacional de Atenas de 1931 (Cardoso Arévalo 2017: 82). El reciente organismo y cuerpo normativo (INPC, LPC) reemplazaron a la Dirección y Ley de Patrimonio Artístico. Notablemente, esta actualización reglamentada mediante el Decreto Ejecutivo 2733 el 9 de julio de 1984 trajo consigo la inclusión de protección a las manifestaciones culturales indígenas y de grupos étnicos culturalmente homogéneos. Veinte años después se codificó la Ley de Cultura y Ley del Patrimonio Cultural que regulaba lo referente a bienes patrimoniales en general, su conservación y preservación (Mejía 2014: 18).

Sin embargo, la gestión de bienes patrimoniales resultaba insuficiente, pues únicamente suponía el análisis del estado de destrucción parcial o total, sin plantear acciones para una conservación pertinente (Cortés Aguirre, Aguirre Ullauri y Contreras Escandón 2019: 3). La situación del patrimonio se agravó a tal punto de debió declararse en emergencia a través del Decreto Presidencial No. 816 del año 2007. Para el año 2008, una reforma a la Constitución Ecuatoriana planteó una nueva configuración del Estado (Martínez Dalmau 2017: 84), y con ello nació una visión sumamente diferente del patrimonio cultural. Los ciudadanos se volvieron sujetos con derechos culturales y se buscó generar políticas públicas culturales y sectoriales para las artes y creatividades (García Cordero 2020: 11).

A partir de esa ley, para rescatar y prevenir futuras amenazas se creó un registro de los bienes patrimoniales usando una base de datos denominada ABACO (Sistema de Información para la Gestión del Patrimonio Cultural), con acceso público a través de la red del INPC (Andrade 2016: 235). En el año 2011, mediante Decreto No. 1014, se propuso la reestructuración de la gestión pública institucional mediante la implementación del SIPCE (Sistema de Información para la Gestión del Patrimonio Cultural) (Sandoval 2017: 10). Con él, el Estado buscó establecer una estructura clara, equipada con herramientas enfocadas a evitar estrategias de intervención negativas a nivel urbano y rural.

En cuanto a la gestión de bienes patrimoniales, uno de los problemas identificados fue la infravaloración y el deterioro físico que sufrían. Por tanto, la gestión de recursos económicos supone un obstáculo al no existir alcances técnicos para registrar o intervenir. Debido a esta y otras razones, en el 2014 se estableció el Proyecto Emblemático Ciudades Patrimoniales del Ecuador, con plazo de ejecución hasta el 2017 con el objetivo de consolidar una cultura local de gestión patrimonial, es decir, con un alcance hacia la periferia, ya que se propone a los gobiernos municipales y parroquiales como principales actores de la conservación y dinamización de los recursos patrimoniales. Para su implementación, se tomaron como agentes de intervención a 38 ciudades del país con características sociales, culturales, identitarias y económicas que no habían sido valoradas y que eran vulnerables debido a los procesos de desarrollo y a la 
constante necesidad de modernización (MCyP 2014: 3). El proyecto en concreto buscaba reducir obstáculos, identificar el tipo de patrimonio, los tipos de intervención, actividades y presupuestos (MCyP 2014: 3), pero, si bien se consideraban varios territorios periféricos, la cobertura no fue completa, muchos asentamientos fueron excluidos o, si acaso, ligeramente considerados, como es el caso de Sinincay. En 2019 el INPC, el Ministerio de Cultura y Patrimonio y especialistas externos divulgaron la Normativa Técnica para Inmuebles Patrimoniales, norma cuyo objetivo es fortalecer la gestión y orden de procesos en el entorno de la competencia sobre el patrimonio en los GAD encargados de su administración y su relación con el Gobierno Nacional (INPC 2019: 1).

La ciudad de Cuenca comenzó a tomar conciencia de sus bienes patrimoniales a partir de 1975. Desde entonces se han desarrollado cuatro inventarios, especialmente de inmuebles, pese a que posee una vasta diversidad de bienes materiales e inmateriales de conocimiento público. Con el decreto del año 2014, en casos como los núcleos poblacionales de su área periurbana o rural, tales como las parroquias de Ricaurte, El Valle, Baños o Sinincay, se representaron como espacios segregados, en los cuales apenas se reportaron respectivamente 119, 15, 171 y 192 bienes entre inventariados y de interés patrimonial (SIPCE 2020). Es decir, este reporte no reflejó lo sucedido hasta el 2013, cuando terminó el proceso de compilación y enmienda de información patrimonial a nivel nacional

En definitiva, ni el proyecto emblemático Ciudades Patrimoniales del Ecuador ni la norma de 2019 consideran dentro de su marco de estudio a pequeños y periféricos centros poblados como Sinincay. Esto puede deberse a que se carecían de datos provenientes de instituciones pertinentes, por lo que las visitas en campo y la interacción con la comunidad se convierten en aliados a efectos de desarrollar el presente estudio.

b) La visión local: componentes generales y patrimonio arquitectónico entre Cuenca y Sinincay

Desde hace algunas décadas, hablar de patrimonio edificado se relaciona por defecto con los centros históricos, así el límite establecido en torno al Centro Histórico $(\mathrm{CH})$ de Cuenca y sus inmuebles monumentales ha relegado en cierta manera a otras manifestaciones. A su vez, generalmente tampoco se considera el proceso de segregación socio-espacial que generó el desplazamiento de la población ni la creación de patrimonio en otros espacios, menos su propia trascendencia en el ciclo de lo patrimonial en términos territoriales. No obstante, la realidad es que se formaron asentamientos fuera de ese entorno y con ello se creó una arquitectura diferente. Los recursos materiales, económicos y políticos dieron lugar a que lo preexistente se conservase y a que varios estilos se impusieran frente a los tradicionales, como sinónimo de modernidad, opulencia y progreso.
La arquitectura en el $\mathrm{CH}$ de Cuenca ha pasado por distintas etapas gracias a sus medios de producción y a los resultados de su economía. Las primeras viviendas se construyen con mano de obra cañari utilizando sus propias materiales y técnicas. Con el pasar del tiempo, la fusión con la cultura española se hizo presente en los sistemas constructivos y distribuciones espaciales con la inclusión de nuevos materiales (tejas, ladrillos u otros) y técnicas (Muñoz 2015: 59). Desde el siglo XVIII se evidencian viviendas sencillas de inspiración andaluza con distribución general de patio, traspatio y huerta.

Para el siglo XIX, se produce el afrancesamiento de la arquitectura cuencana, marcando el tránsito de la ciudad tradicional y colonial hacia la ciudad de la primera modernidad (Borrero 2006: 116). Las plantas arquitectónicas coloniales no se modificaron de manera sustancial; se presentaron más cambios formales que funcionales y se transformaron algunos elementos estructurales y ornamentales en el interior y en fachadas (Borrero 2006: 118). En esta misma época, la urbe estaba formada por apenas tres jurisdicciones, Matriz, San Blas y San Sebastián, todas localizadas a aproximadamente a 10-12 km de la parroquia de Sinincay, uno de tantos anejos.

Desde entonces y hasta la actualidad priman estilos arquitectónicos implantados en distintos períodos histórico-culturales, frente a los escasos ejemplos vernáculos que sobreviven dentro del Centro Histórico. A diferencia de esto, las viviendas alrededor de Cuenca, denominadas como casas rurales por Jamieson (2003), responden al proceso evolutivo de cada contexto, es decir, a las condiciones sociales, políticas y económicas del ser humano que la produce y las usa (Muñoz 2015: 39). Esta arquitectura en la ruralidad azuaya se relaciona principalmente con la tierra y sus derivados, mientras que las formas y espacios responden a la forma de vida del usuario y su área de implantación (Hermida y Mogrovejo 2011: 14).

De otro lado, a pesar de que no existe un vínculo claro entre la relación jurídica de Cuenca y Sinincay, se puede constatar que Sinincay ha mantenido dependencia histórica, aunque posee características y condiciones particulares. Así, el sitio en estudio, emplazado a 2760 $\mathrm{m}$ s. n. m., es un pequeño centro poblado con una traza vial bastante organizado. Su extensión es de 4683 ha., de cuya superficie 34,63 ha le corresponden a la cabecera parroquial delimitada por las vías externas [Figura 1A]. Hacia el interior se distinguen corredores de crecimiento a lo largo de las vías principales que conectan al asentamiento con Cuenca y Racar. Los ríos Sinincay y Negrillo limitan el crecimiento horizontal de la parroquia hacia el sur y el este respectivamente, por lo que la expansión parroquial se orienta sobre todo hacia el noreste [Figura 1B], territorio cuyas pendientes varían entre el 0 y 5 \% (Zambrano y León 1993: 24). 


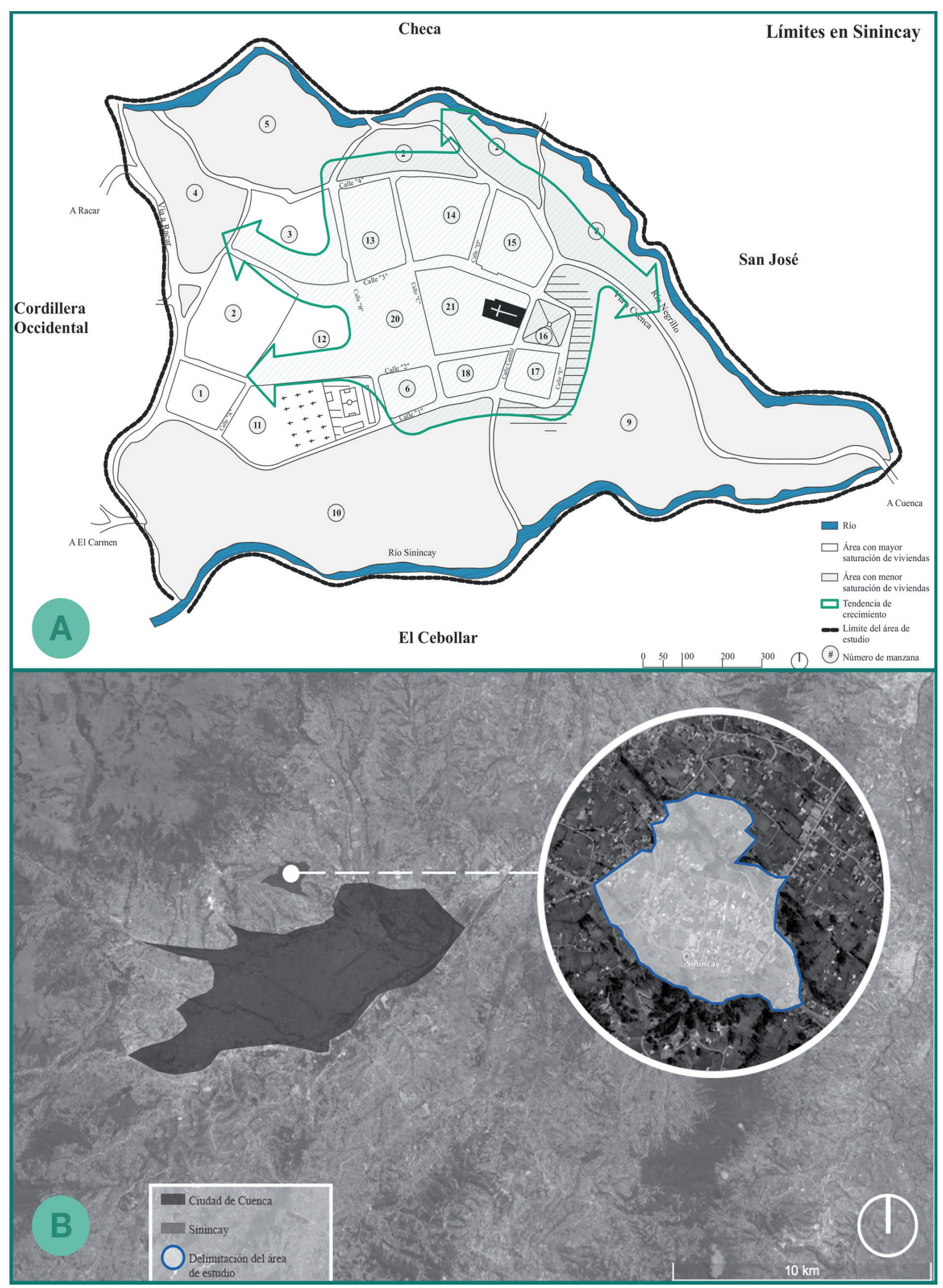

Figura 1.- (A) Delimitación del área de estudio. Fuente: Google Earth. (B) Tendencia de crecimiento. Fuente: Simard 1997. Elaboración: García Cordero 2020. 
Según Terán (1970), Sinincay también se distingue por sus diversas canteras y variados travertinos en explotación activa desde 1830. Las tejas y ladrillos, descritos como perfectos y de excelente calidad gracias a su tradicional técnica de elaboración (García Cordero, 2020: 53), son parte importante del sector productivo, es decir, los dos segmentos materiales constituyen una de las características más importantes de la parroquia (Terán 1947: 128). Pese a este próspero escenario en cuanto a la edificación, el asentamiento ha pasado por varios procesos de transición producto de diversas influencias y aspiraciones.

A nivel urbano, Sinincay presenta dos niveles de ocupación que dividen al territorio en consolidado y en proceso de consolidación. El centro urbano forma parte de la sección consolidada con la mayor densidad poblacional, cuyo uso de suelo está destinado al sector residencial, comercial, equipamientos y de gestión (Zambrano y León 1993: 12). La arquitectura de esta zona, al igual que aquella en proceso de consolidación, incluye como materiales el adobe, la madera, el ladrillo, la tierra, la teja, la piedra, el travertino, la cal y el bahareque, si bien predominan el adobe, el ladrillo, la teja y la madera (García Cordero 2020: 58).

La estructura económica de la parroquia se ve liderada por la industria manufacturera, el comercio, la construcción y actividades del sector primario (Gobierno Autónomo Descentralizado [GAD] de Sinincay 2015: 202). El sistema agrario, en cambio, se caracteriza por la existencia de minifundios acompañados de una predominante presencia campesina dedicada al cultivo de su parcela con productos de consumo familiar. Por ello, pasa a ser de subsistencia o autoabastecimiento, generando únicamente valores de uso (Zambrano y León 1993: 28). Asimismo, al igual que en otras zonas rurales del Ecuador, el desempleo es un problema latente que alcanza el 2,09\%, según análisis realizados en el Plan de Ordenamiento Territorial del año 2015 (GAD de Cuenca 2015: 334), lo que ha desembocado en fenómenos como la migración que representa el 4,72 $\%$ de la población residente hacia el año 2014 (GAD de Sinincay 2015: 187).

Con respecto a los bienes patrimoniales de la parroquia, se reconoce que existen problemas como el desinterés cultural, el descuido por los espacios recreativos y la presencia de proyectos culturales que no están diseñados para satisfacer la demanda de la población. Como excepción a la regla, la Iglesia Católica de San Francisco de Sinincay, construida por la comunidad en 1874 (S. Maza, comunicación personal, 23 de mayo de 2019), es una de las edificaciones con la que más se identifican sus habitantes: se sienten parte de ella, pues fue construida por sus antepasados.

La parroquia también posee otras potencialidades, aunque se encuentren severamente disminuidas.
Destacan el paisaje y la diversidad productiva asociada, condiciones que hacen ver al asentamiento como un escenario óptimo para proponer alternativas de intervención diferentes a la tradicional visión centroperiferia (García Cordero 2020: 11). Para esto, se pueden usar modelos morfotipológicos de la arquitectura patrimonial bajo el concepto de patrimonio como recurso de desarrollo.

\section{Materiales y métodos}

En la arquitectura, el tipo y la forma son estudiados desde hace varios años atrás con referentes como Chueca (1982) y Cannigia y Maffei (1995). A partir de ellos, también se introduce el estudio estratigráfico desarrollado por Andrea Carandini para el estudio de vestigios arqueológicos, con lo que se ampliaba el conocimiento del contexto, el tipo de técnicas constructivas o de acabados, entre otros aspectos (Parenti 1995:20).Con este método, se logra comprender tanto la composición original como los componentes que se agregan a una edificación como respuesta a distintos procesos de la contemporaneidad, lo que ayuda a comprender las diversas etapas temporales de las edificaciones y el aporte o agravio derivado.

Sibien dichos estudios se han establecidoyevolucionado de forma considerable, se ven relacionados con un concepto bastante actual que considera al patrimonio como un potencial para el desarrollo de los territorios. De hecho, Prats (2003) estableció que los bienes patrimoniales se han convertido en un destino estratégico para varias comunidades, principalmente las rurales. Los bienes pasaron a convertirse en fuentes de ingresos y activación económica, convirtiéndose así en recursos culturales (Zamora 2011: 108). De esta manera, gracias a estrategias de conservación específicas se pueden generar beneficios políticos y sociales.

La legislación y las normas de Ecuador en cuanto a derechos culturales han atravesado varios procesos y han llegado a abarcar al patrimonio y a incidir directamente en su administración, pero no han considerado los puntos débiles que todavía están presentes tras la implementación del SIPCE, como punto de partida para la mejora de la gestión patrimonial en el país. El sistema cuenta con guías para el levantamiento de la información, así como con el Instructivo para fichas de Registro e Inventario de Bienes Inmuebles del INPC (2011). Tales metodologías pueden replicarse y adaptarse, pero al estar pensadas a nivel de ciudad no pueden utilizarse directamente para entornos rurales. Es por ello que la metodología aplicada en el presente estudio, aunque parte de herramientas existentes, se ajusta a la realidad de Sinincay. De esta manera, las herramientas podrían aplicarse en asentamientos de naturaleza y características similares. 


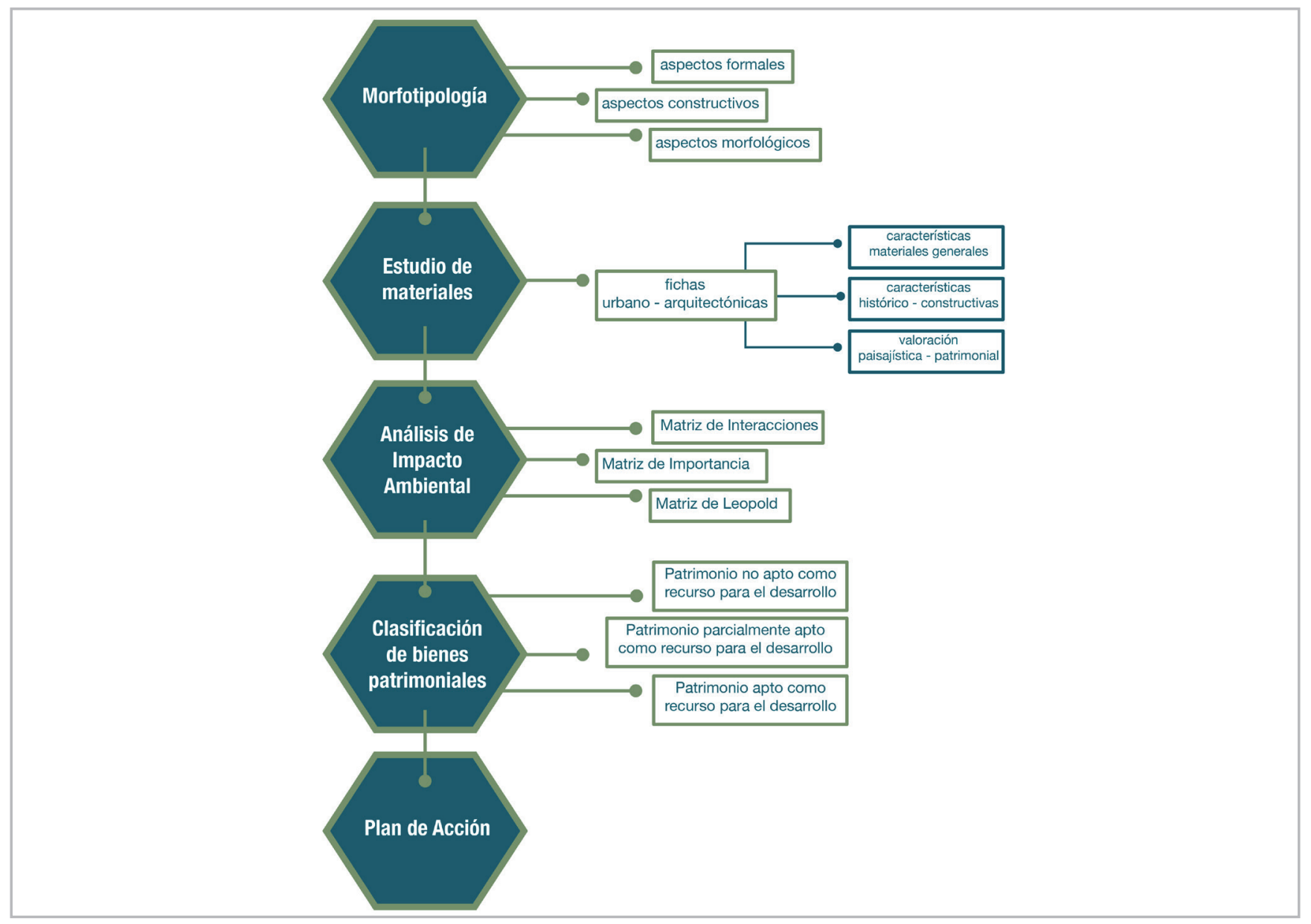

Figura 2.- Fases para el análisis de casos de estudio. Fuente y elaboración: Autor.

A detalle, el trabajo investigativo usa herramientas metodológicas orientadas a: (a) analizar la morfotipología en la cabecera parroquial de Sinincay, (b) estudiar las características espaciales y materiales de casos representativos, (c) evaluar los efectos de los factores del medio al aplicar herramientas ambientales, y (d) establecer categorías para clasificar los bienes estudiados y su posible función como agentes para el desarrollo. En términos procedimentales se establecieron cinco fases que pretenden abarcar las técnicas e insumos necesarios para el análisis: (1) identificación y selección de casos de estudio, (2) análisis y determinación morfotipológica, (3) análisis de impacto ambiental, (4) clasificación de bienes patrimoniales, y (5) plan de acción [Figura 2].

Para comprender la estructura del área de estudio y la línea base se efectuó un análisis cualitativo histórico comparado básico mediante la recopilación y análisis de datos geográficos, sociales, patrimoniales, ambientales y urbano-arquitectónicos provenientes de fuentes secundarias en general. También se incluye el estudio de documentos de especial interés como los proyectos para la educación y socialización del patrimonio rural en Rota (Cádiz), y el proyecto para la conservación y restauración en la comunidad rural de Oaxaca, a manera de casos similares. Otros documentos de tipo científico y académico permiten comprender la gestión del patrimonio en la periferia a nivel local y externo y la posible actuación de este como un recurso de desarrollo. Finalmente, se trabajó con gráficos y diagramas para comparar y visualizar los datos.

\section{— FASE 1: identificación y selección de casos de estudio}

Previo a la aplicación de la estrategia investigativa descrita, es importante indicar que, en cuanto a los bienes patrimoniales, el INPC identifica en Sinincay dos tipos: bienes inventariados y de interés. En el primer caso, pertenecen al período constructivo 1900-1999, lo que los lleva a tener características similares. Y, en el segundo caso, el estudio no considera viable su inclusión debido a la falta de información, en consecuencia, la investigación se desarrolla en torno a los primeros.

Frente al gran número de bienes identificados se procedió a seleccionar los sitios de estudio y se establecieron tres categorías territoriales: (a) anillo en torno a la plaza central, (b) edificaciones de interés parcial, y (c) edificaciones de interés [Figura 3]. Para la clasificación, también se consideraron las propiedades paisajísticas y geográficas [Tabla 1]. En inicio, se procedió a verificar in-situ la información proporcionada por el INPC según las Fichas de Registro del año 2013. Una vez comprobados los 13 bienes inventariados, se reconocieron 


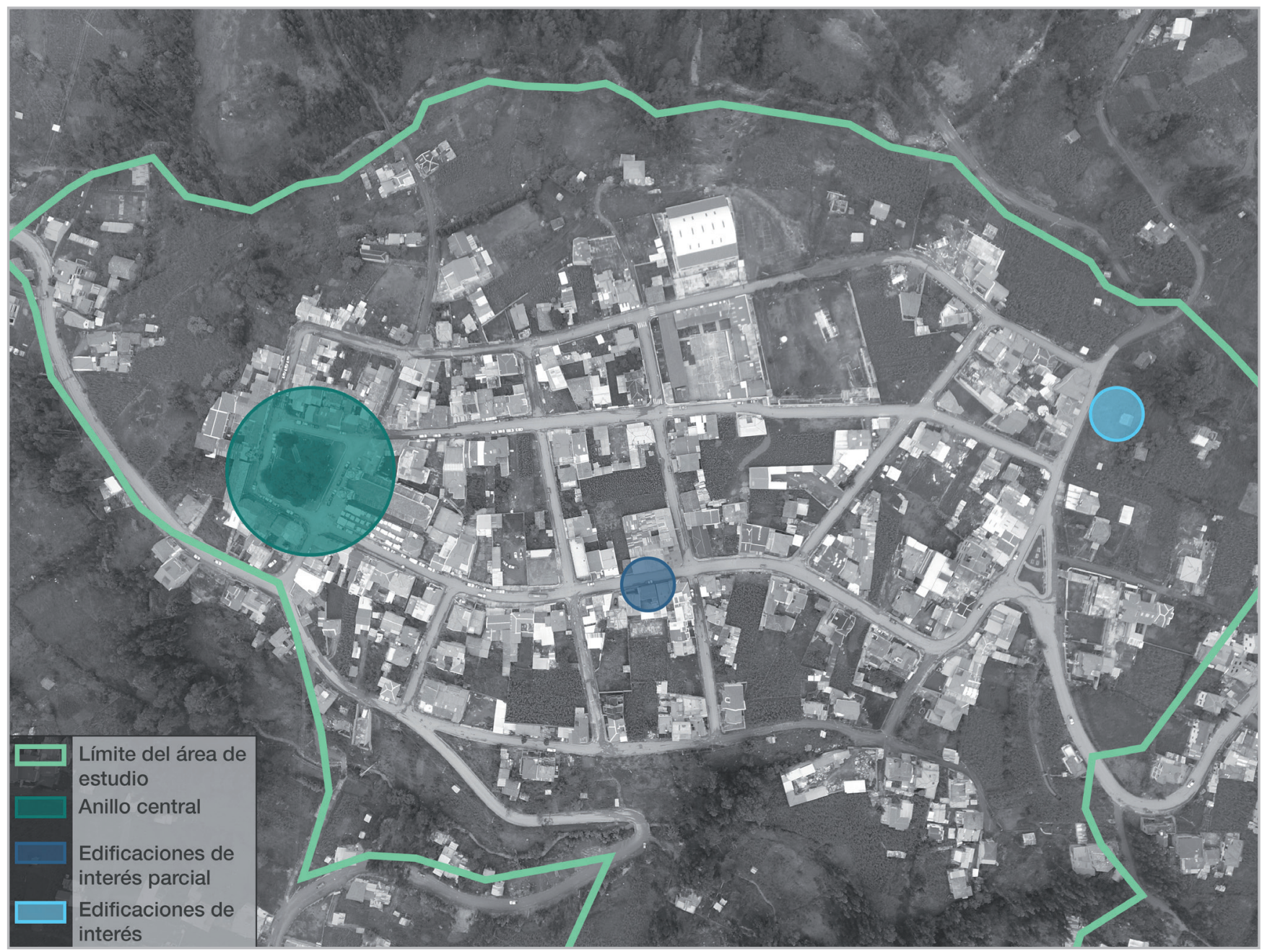

Figura 3.- Categorías de análisis. Fuente y elaboración: García Cordero 2020.

\begin{tabular}{|c|r|c|r|}
\hline \multicolumn{2}{|c|}{ Condicionante geográfica } & \multicolumn{2}{c|}{ Condicionante paisajística } \\
\hline Distancia a la plaza central & Vegetación \\
\hline $0-150 \mathrm{~m}$ & 1 & Sin presencia & 1 \\
\hline $150-300 \mathrm{~m}$ & 2 & Presencia & 2 \\
\hline $300-450 \mathrm{~m}$ & 3 & Presencia y actividad agrícola & 3 \\
\hline
\end{tabular}

Tabla 1.- Condicionantes para la clasificación de casos de estudio. Fuente y elaboración: García Cordero, 2020

11 bienes adicionales, reportando un total de 24 en la cabecera parroquial.

De otrolado, también se buscó comprender las características espaciales y materiales que identifican, valoran y catalogan los bienes arquitectónicos en articulación con el posible patrimonio inmaterial. Con este fin, se recurrió al levantamiento en campo, un estudio etnográfico, talleres comunitarios, el levantamiento fotográfico y la aplicación de fichas urbano-arquitectónicas con componentes ambientales [Figura 4]. Los resultados se interpretaron mediante gráficas estadísticas tomando como referencia
The ABC Method (Canadian Conservation Institute e ICCROM 2016: 121) y en atención a las condiciones y características del estudio.

Tanto el levantamiento de información en campo como el trabajo con la comunidad son cruciales para conocer la opinión colectiva y el valor social asociado a los bienes. De hecho, la opinión comunitaria es un factor relevante para una futura intervención, por ello y para conocer la evolución del asentamiento y el vínculo que existe con el patrimonio se definió un grupo focal. Según las consideraciones de Escobar y Bonilla Jiménez (2017), el número ideal de participantes varía entre 3 y 12, por lo que, al considerar el alcance de la investigación y la información existente, se trabajó con 12 habitantes pertenecientes a la cabecera urbana de la parroquia y comunidades. Para recolectar los datos deseados se elaboró una encuesta estructurada con base en parámetros concretos: (a) histórico-constructivos, (b) urbanos y (c) de valoración y conocimiento patrimonial.

Finalmente, y una vez aplicadas las herramientas anteriores, se estudiaron todos los casos ubicados en el anillo central [Figura 3], debido a la importancia espacial y social de dicha área administrativa, a excepción de los equipamientos 


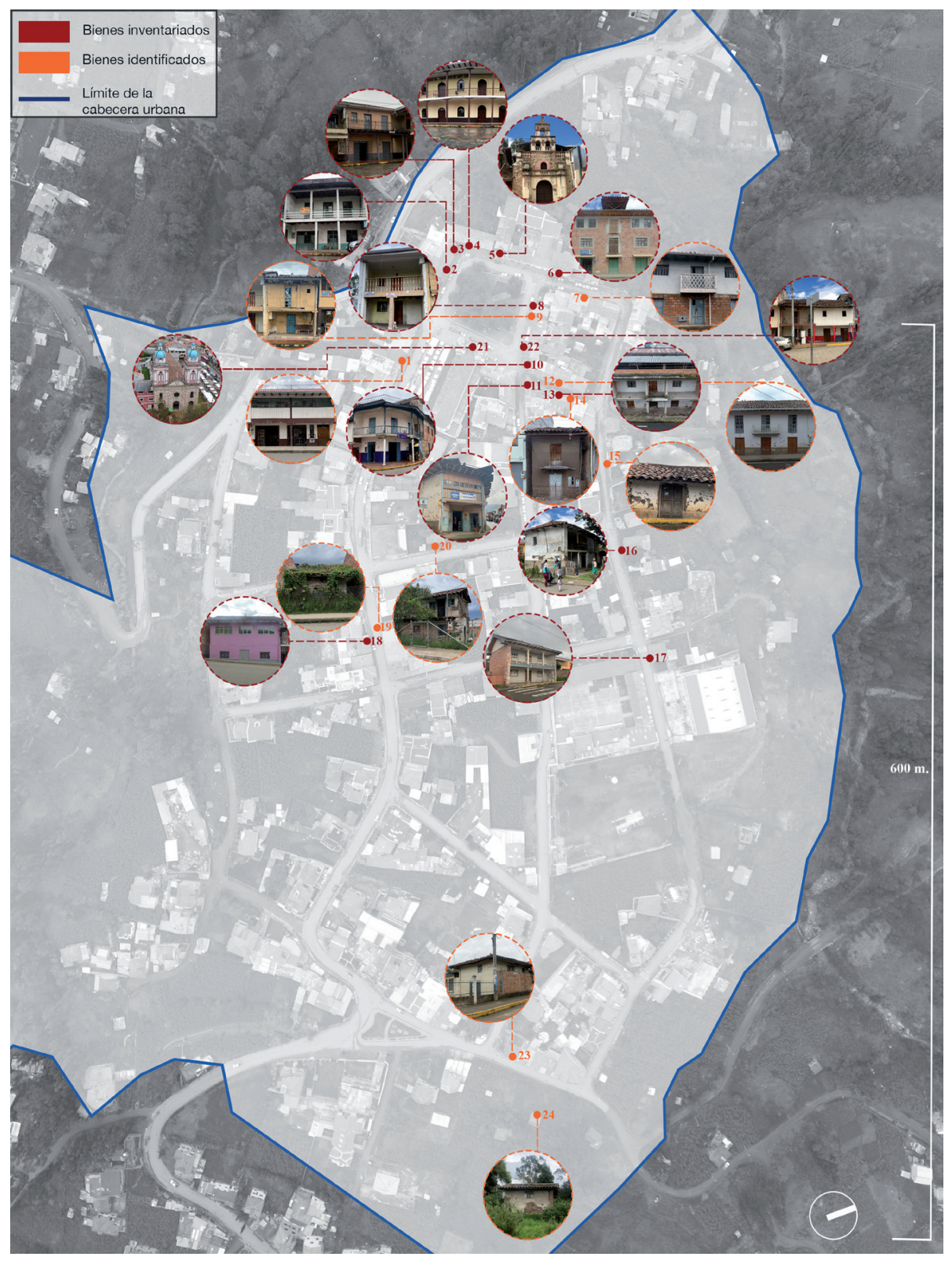

Figura 4.- Bienes inventariados e identificados. Fuente: INPC 2009-2017. Elaboración: García Cordero 2020.

de culto, cuyas cualidades no se adaptan a los fines de la investigación. Para las edificaciones localizadas fuera del anillo central, se tuvieron en cuenta aquellos casos con mayor representatividad tras aplicar los parámetros establecidos.

\section{— FASE 2: análisis y determinación morfotipológica}

En cuanto a la evolución de la morfotipología, el entorno construido, sus materiales y formas están directamente asociados con procesos históricos particulares. Las formas arquitectónicas son capaces de evidenciar las circunstancias del momento en el que fueron construidas, pues mantienen una estrecha relación con las costumbres, tradiciones y aspectos políticos de dicha época. Con base en ello, se propusieron cinco periodos capaces de relacionar la arquitectura con eventos, hechos históricos o con fenómenos económicos y sociales [tabla 2]. En adelante, en cada una se determinan aspectos formales, constructivos y morfológicos de singularidad local.

De otro lado, el análisis de las características generales e histórico-constructivas, es decir, para comprender las formas y características del patrimonio periférico se aplicaron fichas arquitectónicas que consideraron las propiedades histórico-constructivas y la identificación de lesiones patológicas visibles en el paramento frontal. Por consiguiente, se establecieron tres componentes para diagnosticar los materiales: (1) estado de conservación, (2) lesiones patológicas y (3) relaciones históricoconstructivas. Como complemento, se insertó la valoración paisajística-patrimonial del bien inmueble y el predio de implantación [Figura 5]. 


\begin{tabular}{|c|c|c|}
\hline \multicolumn{2}{|c|}{ Períodos establecidos para el análisis } \\
\hline Periodo & Subperiodo & Descripción \\
\hline & $1930-1939$ & Primeros indicios arquitectónicos \\
\hline Prereforma agrícola & $1939-1949$ & Industrialización de la producción \\
& $1950-1959$ & Cambios regionales \\
\hline Boom petrolero & $1960-1969$ & Bonanza económica nacional \\
\hline Crisis económica y migración & $1980-1989$ & Bonanza económica \\
\hline Crisis económica y dolarización & $1989-1999$ & Cambio de moneda y crisis económica \\
\hline Reactivación económica & $2000-2019$ & Recuperación productiva. El PIB crece hasta el 27,9\% \\
\hline
\end{tabular}

Tabla 2.- Períodos de análisis. Fuente: Zambrano y León, 1993. Elaboración: García Cordero 2020.

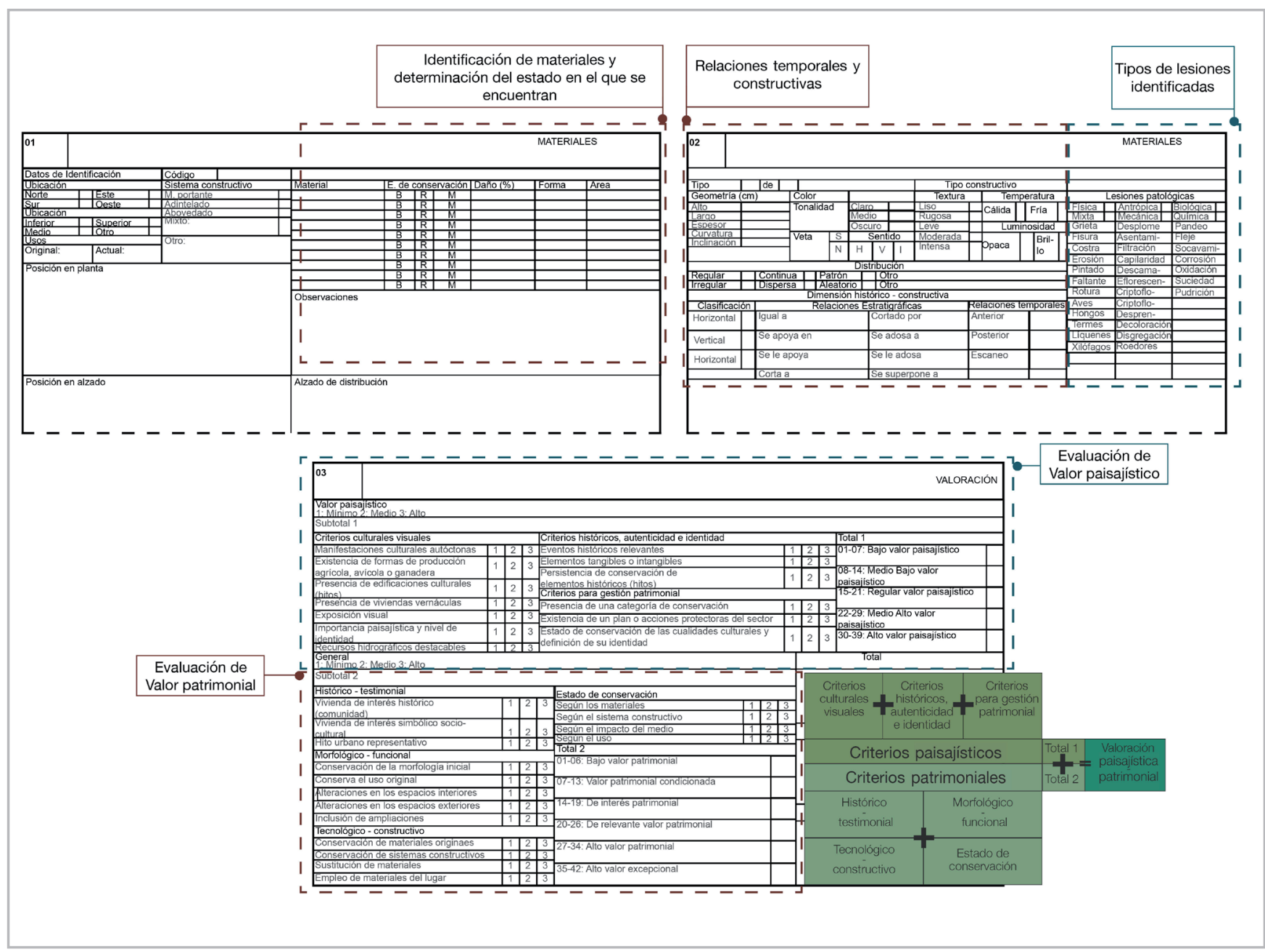

Figura 5.- Fichas urbano-arquitectónicas. Fuente: Aguirre Ullauri, 2017. Elaboración: García Cordero, 2020.

El sistema de valoración establecido en las fichas está basado en los criterios del Instructivo para fichas de Registro e Inventario de Bienes Inmuebles del INPC (2017) y lo expresado por Cambón (2009), quien se refiere a los paisajes culturales como sitios capaces de producir una interacción armónica entre elementos naturales y culturales. Se consideró, por tanto, el valor mínimo, o la presencia o manifestación baja o nula del criterio establecido; valor medio o la presencia o manifestación moderada del criterio planteado, y valor alto, o gran presencia del criterio planteado.

\section{_ FASE 3: análisis de impacto ambiental}

Para determinar el impacto de los agentes del medio en la arquitectura a través de los materiales se adaptaron y se aplicaron de manera integral las Matrices de Interacciones, 
Importancia y Leopold, con base en la metodología planteada por Aguirre Ullauri et al. (2017). Además, al estudiar los distintos factores de afección se tomó el modelo de Coria (2008), esto es, una matriz con 33 factores impactados y 20 impactantes. Además, en conformidad con los fines de la investigación, la dinámica de la matriz base se modificó, es decir, se analizó el impacto de los factores del medio en los materiales de las edificaciones patrimoniales para lo que se determinaron 20 factores impactantes y 13 impactados; la relación entre cada uno de ellos se realizó de manera individual. En conjunto, destacan como segmentos procedimentales la aplicación de:
- Matriz de interacciones: evalúa la interacción entre los agentes del medio como factores de riesgo (variables impactantes) y los elementos de interés (variables impactadas), en este caso los materiales de los casos de estudio, y se estableció una relación de incidencia [Figura 6A]. Las variables impactantes se estiman con 1, cuando representan afección, y con 0 en caso contrario. Luego se establecieron relaciones evidentes entre los objetos estudiados y los factores de análisis para poder plantear estrategias protectoras (Coria 2008: 128). Las variables utilizadas se seleccionaron de acuerdo con las características del área de estudio [Figura 6B].

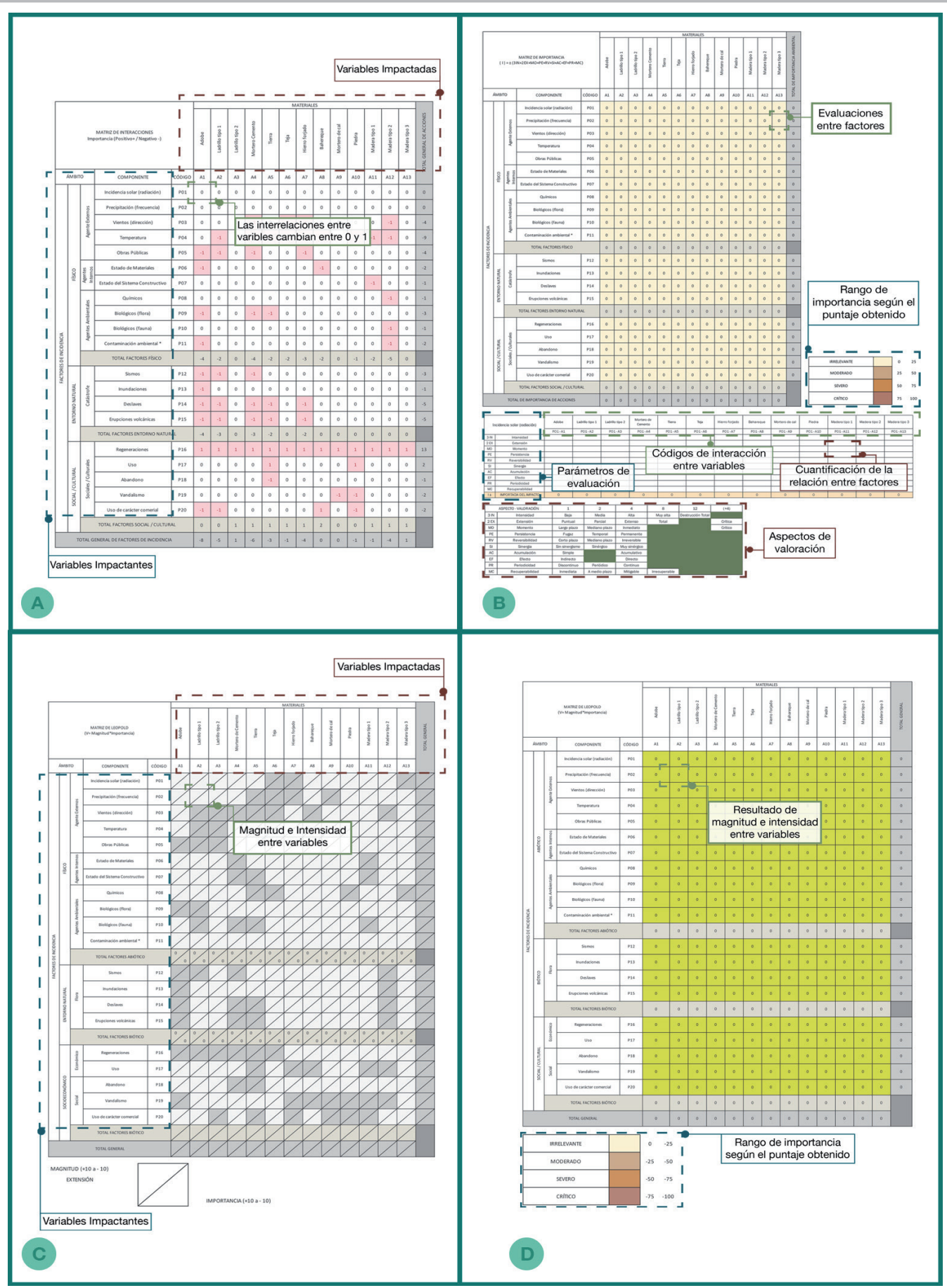

Figura 6.- Matrices para el Análisis de Impacto Ambiental. (A) variables y relaciones, (B) evaluaciones, (C) evaluaciones Matriz de Leopold, y (D) resultados de la Matriz de Leopold Fuente: Coria 2008. Elaboración: García Cordero 2020. 
- Matriz de importancia: se desarrolló con los mismos criterios de la matriz previa, es decir, relacionando los factores de incidencia con los materiales identificados de manera cualitativa y cuantitativa; para ello se aplicó la fórmula (1) propuesta por Coria (2008):

$$
\mathrm{I}=3 \mathrm{i}+2 \mathrm{EX}+\mathrm{MO}+\mathrm{PE}+\mathrm{RV}+\mathrm{SI}+\mathrm{AC}+\mathrm{EF}+\mathrm{PR}+\mathrm{MC}
$$

Las abreviaturas hacen referencia a: I, importancia; 3i, intensidad; $E X$, extensión; $M O$, momento; $P E$, persistencia; $R V$, reversibilidad; $S I$, sinergia; $A C$, acumulación; $E F$, efecto; $P R$, periodicidad y $M C$, recuperabilidad.

Para la comparación se definieron 130 valoraciones cuantitativas, por ello se establecieron rangos que respondieron al valor de la comparación entre factores de incidencia. Al final, la evaluación permitió una aproximación a la toma de decisiones, que se concretó en la siguiente fase.

Matriz de Leopold: evalúa la magnitud frente a intensidad de los factores impactantes sobre los materiales de las edificaciones estudiadas con representatividad histórica. El rango de valoración fue de 1 a 10, y posteriormente se aplicó la fórmula (2). En ella, I hace referencia a importancia y $\mathrm{Mg}$ a magnitud.

$$
(\mathrm{I}+\mathrm{Mg} * 100) / 20
$$

También se establecieron niveles de incidencia con rangos y el resultado permitió identificar las medidas que deben tomarse según el nivel de afección y la premura con la que deben realizarse [Figura $6 \mathrm{C}$ y $6 \mathrm{D}$ ].

\section{- FASE 4: clasificación de bienes patrimoniales}

La catalogación de casos de estudio se apoyó en lo establecido por la Guía Metodológica: Iniciativa Ciudades Emergentes y Sostenibles elaborada por el Banco Interamericano de Desarrollo (BID 2016), pero se adaptó a las condiciones de la investigación en cuestión, para lo cual se tomaron en cuenta las fases: (1) preparación, (2) análisis/diagnóstico, (3) priorización y (4) plan de acción [Figura 7], de manera que sea factible establecer categorías capaces de posicionar a los casos de estudio en grupos para generarse escenarios de desarrollo.

El análisis de variables para el Plan de Acción, como último segmento metodológico, se efectuó con fundamento en diversas técnicas aplicadas en ámbitos u objetos de estudio que presentan características relacionadas con los ejes temáticos de patrimonio periférico, impacto ambiental y paisaje; se recurrió a referentes como los Indicadores de Sostenibilidad de la Agenda XXI de Málaga (2011) elaborados por el Ayuntamiento de Málaga y el Programa de Actualización Urbana Barranco (2011) a cargo del GAD de Cuenca. A su vez, el plazo se determinó con base en el PAMAC

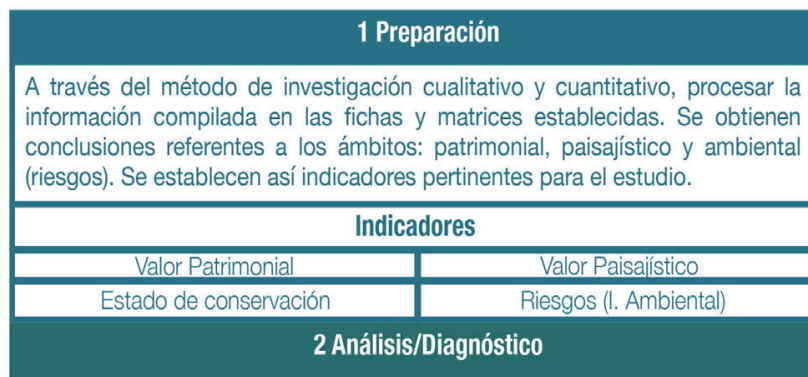

Establecer escenarios que puedan clasificar a los casos de estudio en relación con los filtros (indicadores) por aplicar con las características que presentan.

\section{Priorización}

Aplicación de los filtros establecidos en un modelo cualitativo analitico, que permita clasificar a los casos de estudio dentro de los escenarios establecidos, según el puntaje obtenido, donde:

\begin{tabular}{|l|l|l|l|}
\hline V. Patrimonial & V. Paisajístico & \multicolumn{1}{|c|}{ Riesgos } & E. de conservación \\
\hline $\begin{array}{lll}\text { 1)mínimo: presencia o manifestación, } \\
\text { baja o nula del criterio establecido. }\end{array}$ & $\begin{array}{l}\text { según el impacto del } \\
\text { medio en el material }\end{array}$ & 1) bueno \\
\cline { 1 - 1 } $\begin{array}{ll}\text { 2) medio: presencia o manifestación } \\
\text { moderada del criterio planteado. }\end{array}$ & 1) irrelevante & 2) regular \\
$\begin{array}{llll}\text { 3) alto: gran presencia del criterio } \\
\text { planteado. }\end{array}$ & 3) crítico & 3) malo \\
\hline
\end{tabular}

\section{Plan de Acción}

Formular planes de acción aplicables a cada uno de los escenarios establecidos.

Figura 7.- Esquema para la identificación de escenarios. Fuente: BID 2018. Elaboración: García Cordero 2020.

[Plan de Acción para el Patrimonio Mundial en México y América Central] (2018) y el alcance obedece a la condición de cada bien.

Finalmente, con el objeto de determinar el potencial que presentan los casos de estudio como agentes para el desarrollo en la cabecera parroquial de Sinincay, se establecieron escenarios [Tabla 3]. Cada uno clasificó a los bienes inmuebles de acuerdo con las características arquitectónicas, paisajísticas y ambientales que presenten, y se determinó si son o no aptos como recursos para el

\begin{tabular}{|c|c|c|}
\hline \multicolumn{2}{|c|}{ Patrimonio no apto } & $0-4$ \\
\hline \multirow{3}{*}{$\begin{array}{c}\text { Parcialmente } \\
\text { apto }\end{array}$} & con alto valor paisajístico & \multirow{3}{*}{ 4-8 } \\
\hline & con alto valor patrimonial & \\
\hline & con características mixtas & \\
\hline \multirow{3}{*}{$\begin{array}{l}\text { Patrimonio } \\
\text { apto }\end{array}$} & con alto valor paisajístico & \multirow{3}{*}{$8-12$} \\
\hline & con alto valor patrimonial & \\
\hline & con características mixtas & \\
\hline
\end{tabular}
desarrollo (García Cordero 2020: 80).

Tabla 3.- Tabla 3. Escenarios de aptitud para el desarrollo. Fuente y elaboración: García Cordero 2020. 


\section{— FASE 5: Plan de Acción}

El trabajo con el grupo focal y las visitas in situ facultaron identificar problemas como el uso inadecuado de edificaciones patrimoniales, intervenciones incorrectas y abandono. Para resolverlo, se plantearon variables y metas y se estableció un plazo de cuatro años desde el 2020 como línea base y tomando como referencia al PAMAC (2018). Las metas [Figura 13A] se definieron de este modo: (1) mejorar el estado de materiales en bienes inmuebles patrimoniales por medio de acciones que recuperen adecuadamente, pero de manera inicial, las fachadas e incluyan el cuidado pertinente, (2) optimizar el área verde para disfrute de los habitantes, a través del incremento de espacios didácticos en los que interactúen el usuario con el medio, (3) regular los impactos ambientales sobre los edificios para lograr una mejor calidad urbana, y (4) reforzar el conocimiento de bienes patrimoniales para generar sentimiento de empoderamiento (García Cordero 2020: 88).

Es evidente la importancia de la instrucción sobre el cuidado y tratamiento del patrimonio para la recuperación y conservación. Para evitar el deterioro de los bienes, lo que simultáneamente afecta a la imagen urbana del asentamiento, se propone el plan de acción denominado Conservando el Patrimonio en Sinincay, el cual tiene como objetivo principal mejorar la calidad de vida de los habitantes a partir de potenciar sus bienes patrimoniales como recursos para el desarrollo a partir de programas y proyectos. Al establecer a un inmueble patrimonial como agente para el desarrollo, se garantiza su conservación al tiempo que se aporta al progreso del asentamiento en el que se encuentra, por eso es vital reactivar los usos o plantear nuevos que mantenga la interacción con el medio, acoplando características y condiciones de la contemporaneidad.

Una vez proyectado el Plan de Acción, es necesario precisar el monitoreo. Para ello, se tomaron en cuenta la periodicidad establecida en el Programa de Mantenimiento y Conservación de Bienes Inmuebles Patrimoniales, de la Guía Didáctica para Mantenimiento y Conservación de Bienes Inmuebles Patrimoniales (2012). Las acciones que se aplican al estudio son: vigilancia, revisión y comprobación.

\section{Resultados}

A nivel general, en Sinincay el medio natural y el construido presenta características capaces de condicionar el desarrollo de la producción arquitectónica urbana y rural. Los cambios en la forma de vida de la sociedad los han llevado a adaptarse, y particularmente la vivienda rural se ha visto influenciada por la agricultura, la ganadería y la artesanía como las principales actividades productivas. Es decir, el entorno construido, sus materiales y formas están directamente asociados con procesos históricos.

Por su parte, las formas arquitectónicas son capaces de evidenciar las circunstancias del momento en el que fueron construidas, pero a su vez mantienen una estrecha relación con las costumbres, tradiciones y aspectos políticos. De su análisis, se definen períodos concretos que lo ejemplifican:(1) prerreforma [1930-1969], (2) boom petrolero [1970-1979], (3) crisis Económica y migración Internacional [1980-1990], (4) crisis económica y dolarización y (5) reactivación económica. En consecuencia, Sinincay ha pasado por un proceso evolutivo interno plenamente identificable desde 1930. Esta situación no permite definir un modelo morfotipológico específico. No obstante, se reconocen características que representan y diferencian a las distintas épocas e incluso, bajo una comparativa mayor, con edificaciones de otros asentamientos periurbanos, rurales y del $\mathrm{CH}$ de Cuenca, bajo la lógica permanente de dependencia

En cada etapa, las edificaciones muestran la forma de vida de los usuarios y evidencian a través de los espacios su realidad e identidad (Arévalo 2004: 930). En consecuencia, la morfotipología de las edificaciones ha cambiado tanto como la realidad y la identidad. Se puede observar cómo en 89 años las formas y los usos se transformaron en función de las necesidades y demandas impuestas por la contemporaneidad. Progresivamente, los volúmenes adquirieron mayor complejidad, aparecieron elementos como balcones y terrazas que rompen con la perpendicularidad de los muros y marcan la presencia de diversas expresiones formales [Figura 8] en lo que fuera una trama continua predominante.

En el aspecto funcional, la distribución espacial y ocupación están vinculadas a las labores y necesidades de los usuarios, ya que en la historia de cualquier sociedad existen períodos que verifican la transformación o aparición de nuevas actividades en los espacios (Mannoni y Giannichedda 2004: 34). De la misma manera, en el ámbito patrimonial, el estudio de la forma y el tipo muestran rasgos de las actividades productivas características del asentamiento. Destacan las plantas bajas con ambientes polifuncionales, que en periodos posteriores adquieren usos específicos.

Desde 1950 se observa cómo ciertos espacios desaparecen y otros se incorporan. El área de cuyero es sustituida por la tienda, como un espacio con acceso interno y externo, pero sobre todo se presenta al comercio como un uso complementario que se utiliza con frecuencia hasta 1970. Después, el uso exclusivo de vivienda se plantea como prioritario hasta la actualidad [Figura 9, aunque se puede considerar la imitación de procesos externos relacionados con la producción de actividades o servicios que en un principio no se brindan, pero que por la demanda son incorporados.

Lo cierto es que, en la actualidad, las edificaciones reflejan casi en su totalidad rasgos arquitectónicos de contextos ajenos resultado de la migración e influencia de la ciudad, con especial incidencia en el último período. Se trata de líneas rectas y cubiertas planas que dejan de lado la esencia de la construcción vernácula, nuevos modelos constructivos que conservan únicamente al portal adaptándolo, pero que mantienen la función original 


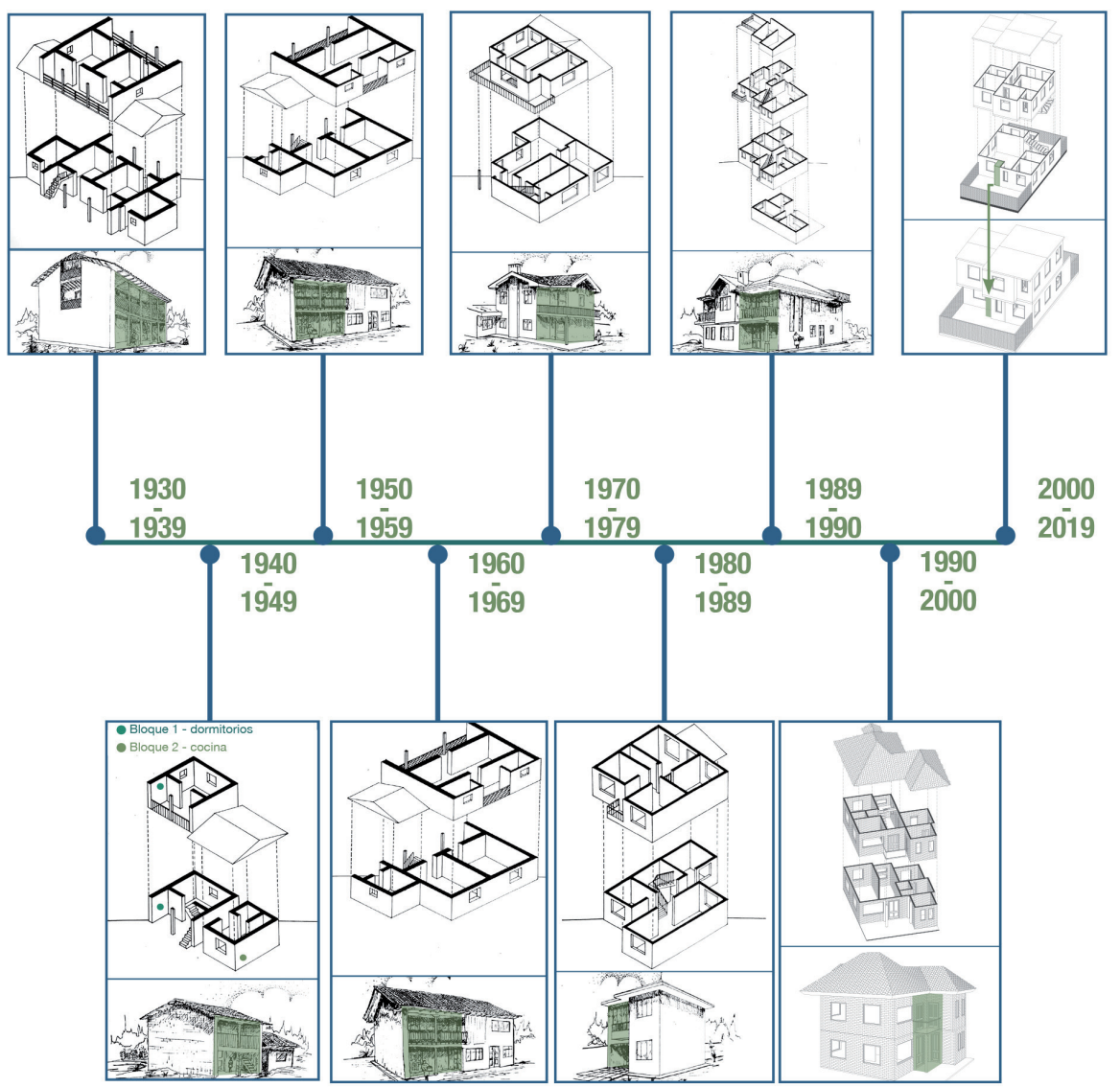

Figura 8.- Morfología 1930-2019. Fuente: Zambrano y León, 1993. Elaboración: García Cordero, 2020.

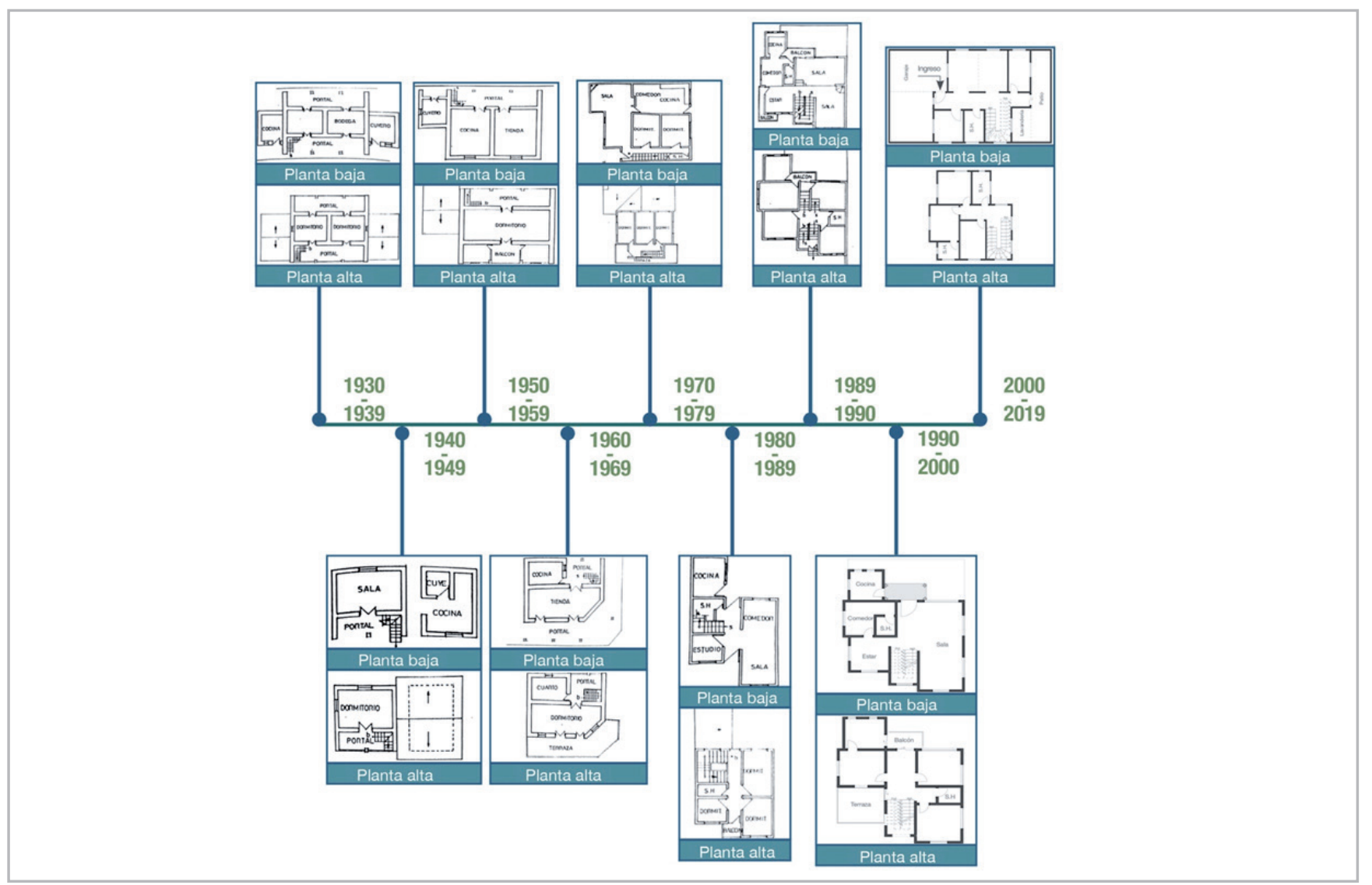

Figura 9.- Usos y espacios. Fuente: Zambrano y León 1993. Elaboración: García Cordero 2020. 
y jerarquizan el ingreso. En la misma línea, el aspecto funcional se excluye y pasa a segundo plano y se construyen proyectos con características globalizadas, aunque los estilos propios están también presentes y responden a las características de la zona en la que se emplaza.

\section{a) Características generales e histórico-constructivas}

En cuanto a los trece bienes patrimoniales estudiados bajo el concepto de patrimonio como recurso de desarrollo, el análisis morfotipológico refleja las características generales e histórico constructivas, los niveles de impacto ambiental y la aptitud como recurso para el desarrollo.

El levantamiento bidimensional de las fachadas y la aplicación de fichas urbano-arquitectónicas [Figura 10] determina que el estado predominante de los materiales es regular en extensión comprendida entre el 25 y el 100 $\%$ según el caso correspondiente. A su vez, se identificaron materiales en estado bueno y malo en porcentajes hasta del $75 \%$ y $40 \%$, respectivamente [Figura 11B]. Las

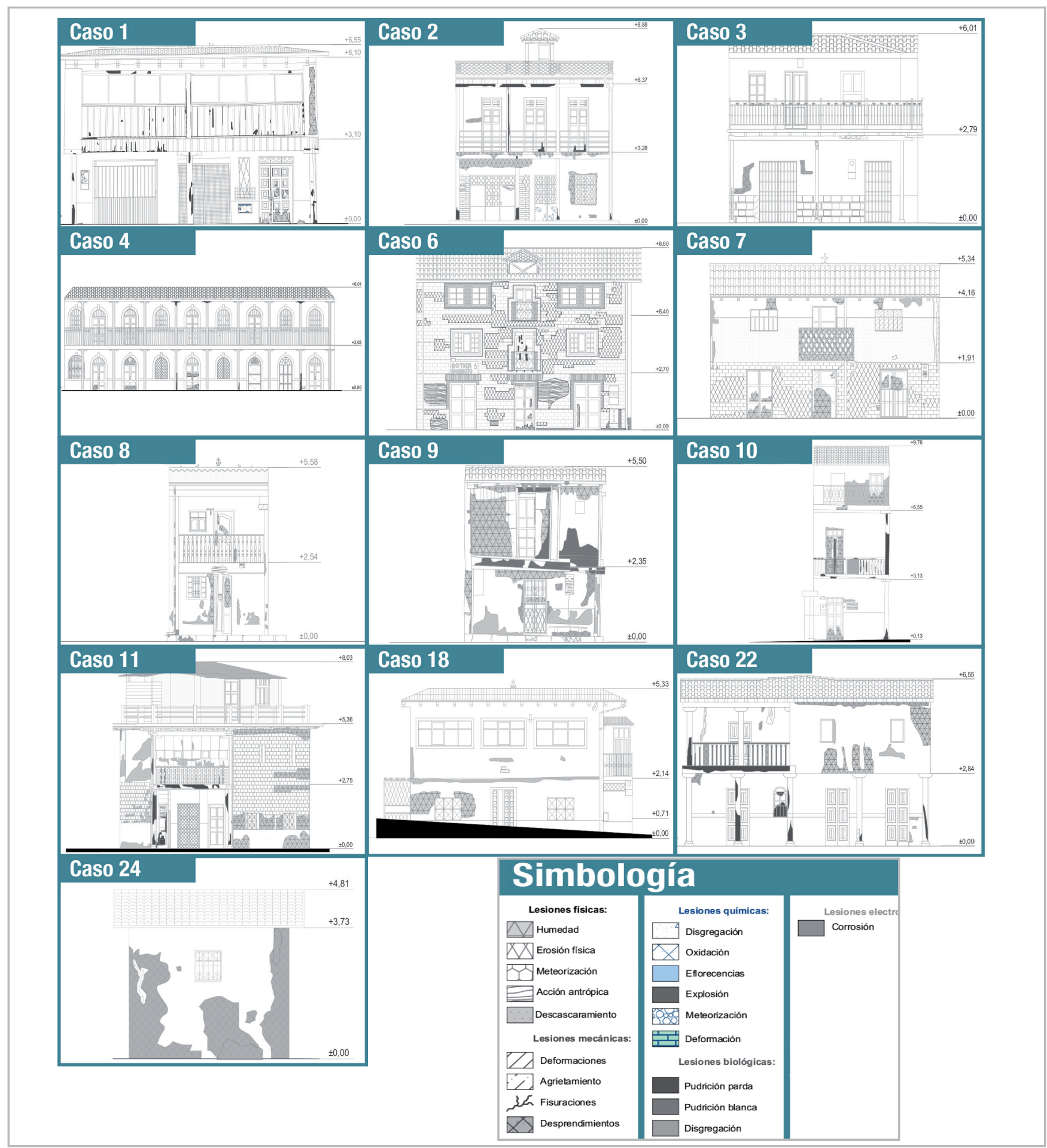

Figura 10.- Levantamiento de fachadas e identificación de lesiones patológicas. Fuente: García Cordero 2020. 
lesiones patológicas con mayor frecuencia son la pudrición blanca y parda, la humedad, presencia de fisuras, erosión, desprendimiento y descascaramiento. A su vez, en el componente de valoración prima el valor paisajístico medio alto y alto en valor patrimonial.

b) Impacto ambiental

La interacción, importancia e intensidad del impacto del ambiente en los materiales identificados muestra reacciones diversas, ya sea irrelevante, moderado o severo [Figura 11A]. En el primer caso, representa entre el 53 y $83 \%$ de los impactos totales, en el segundo entre el 14 y $38 \%$, y en el escenario final, entre 0 y $18 \%$ [Figura $11 \mathrm{C}$ ]. Es importante prestar atención especial a los impactos clasificados como moderados, ya que, al no tratarse con tiempo, pueden ascender al siguiente grupo y representar un mayor problema para el material y eventualmente para la edificación.

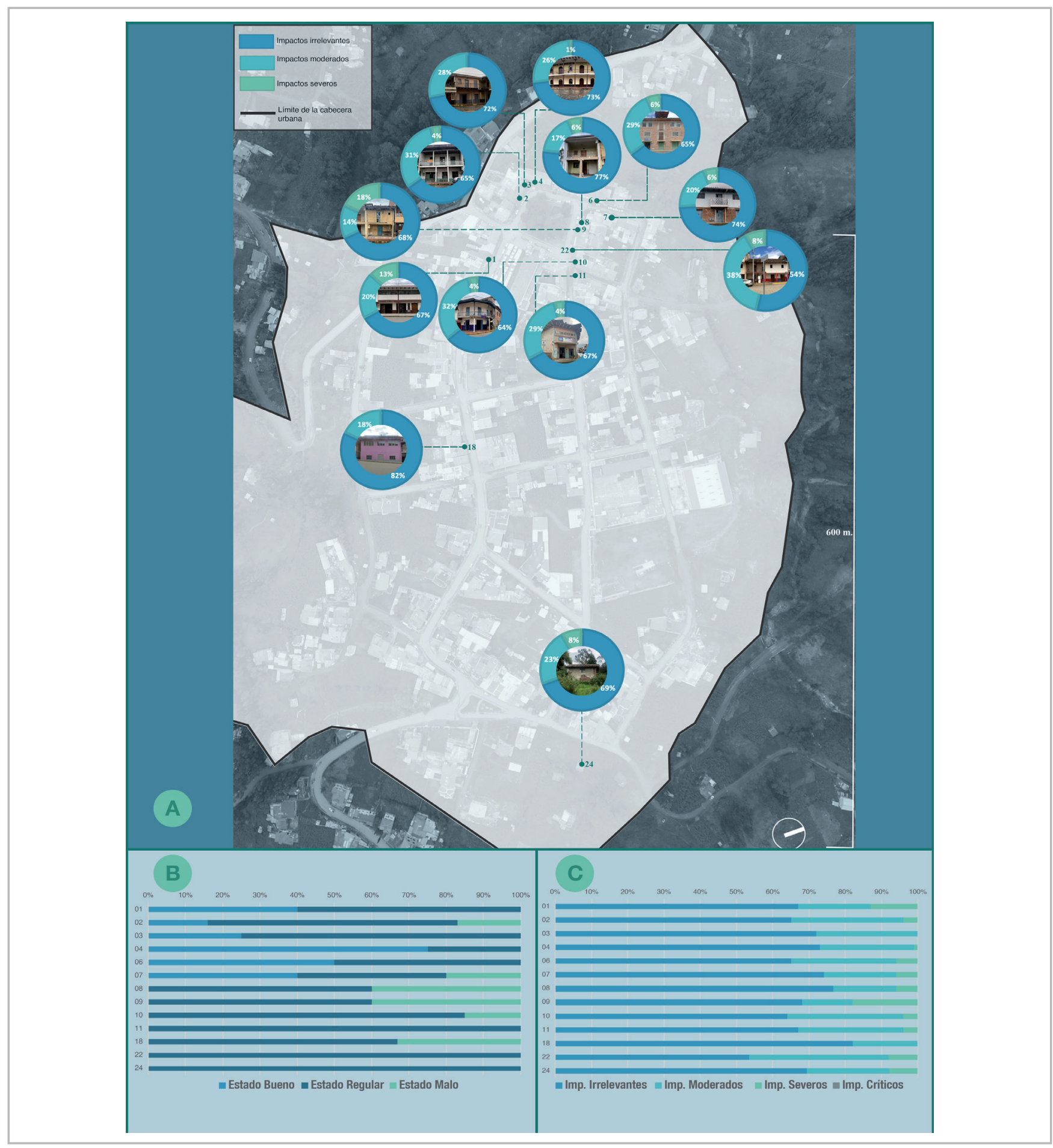

Figura 11.- (A) Impacto ambiental por caso de estudio. (B) Estado de materiales. (C) Impacto del medio por caso de estudio. Fuente y elaboración: García Cordero 2020. 


\section{c) Aptitud como recurso para el desarrollo}

Los cuatro indicadores pertinentes al estudio: (a) valor patrimonial, (b) valor paisajístico, (c) estado de conservación, y (d) riesgos, indican que el $31 \%$ de los casos se enmarcan en el escenario parcialmente apto como recurso de desarrollo, mientras el $69 \%$ representa a los recursos aptos [Tabla 4].

\begin{tabular}{|c|c|c|c|}
\hline \multicolumn{3}{|c|}{ Patrimonio no apto } & 0 \\
\hline \multirow{3}{*}{$\begin{array}{l}\text { Parcialmente } \\
\text { apto }\end{array}$} & Caso 07 & Caso 08 & \multirow{3}{*}{5} \\
\hline & Caso 18 & Caso22 & \\
\hline & \multicolumn{2}{|c|}{ Caso 24} & \\
\hline \multirow{4}{*}{$\begin{array}{l}\text { Patrimonio } \\
\text { apto }\end{array}$} & Caso 01 & Caso 02 & \multirow{4}{*}{8} \\
\hline & Caso 03 & Caso 04 & \\
\hline & Caso 06 & Caso 09 & \\
\hline & Caso 10 & Caso11 & \\
\hline
\end{tabular}

Tabla 4.- Clasificación de casos de estudio orientados hacia el desarrollo. Fuente y elaboración: García Cordero 2020.

Con esta base, se identificaron problemas urbanos, económicos y patrimoniales y se evidenció la planificación de un espacio subordinado por el centro urbano de mayor jerarquía. La planificación con base en los conceptos de la centralidad frente a la falta de recursos no permite que la gestión pública cumpla su rol de manera eficaz y eficiente. Por lo tanto, el Plan de Acción Conservando el Patrimonio en Sinincay [Figura 12B] y los proyectos particulares buscan cortar la visible dependencia entre Sinincay y Cuenca.

Estos proponen estrategias capaces de mitigar los problemas y convertirse en una clara ruta hacia el progreso como realidad y no como utopía. Sus tácticas potencian los bienes patrimoniales a servicio de la comunidad y sus potencialidades reconocibles.

\section{d) Estrategias hacia el desarrollo}

El Plan de Acción Conservando el Patrimonio en Sinincay busca mejorar la calidad de vida de los habitantes con la iniciativa de comenzar a potenciar los bienes patrimoniales como recursos de desarrollo. En primer lugar, al identificarse problemas económicos, políticos y patrimoniales es evidente la planificación de un espacio bajo el orden del centro urbano de mayor jerarquía. En consecuencia, se plantean proyectos que manejan al patrimonio como instrumento para desvincular la dependencia administrativa [Figura 13] y crear una ruta sólida para el crecimiento y conservación del asentamiento (García Cordero 2020: 124).

Dos proyectos en concreto apoyan este escenario. El primero es Aynikui: artesanos en Sinincay que reposiciona a la artesanía como una importante actividad económica que ahora no se aprovecha adecuadamente. El segundo es Huk'i Cultural que pretende mantener vivo el patrimonio cultural material e inmaterial a través de la inclusión de áreas para difusión y juegos tradicionales; es decir, se trata de fomentar el tratamiento, valoración y conservación del patrimonio con espacios que recuperan el vínculo con los habitantes (García Cordero 2020: 148).

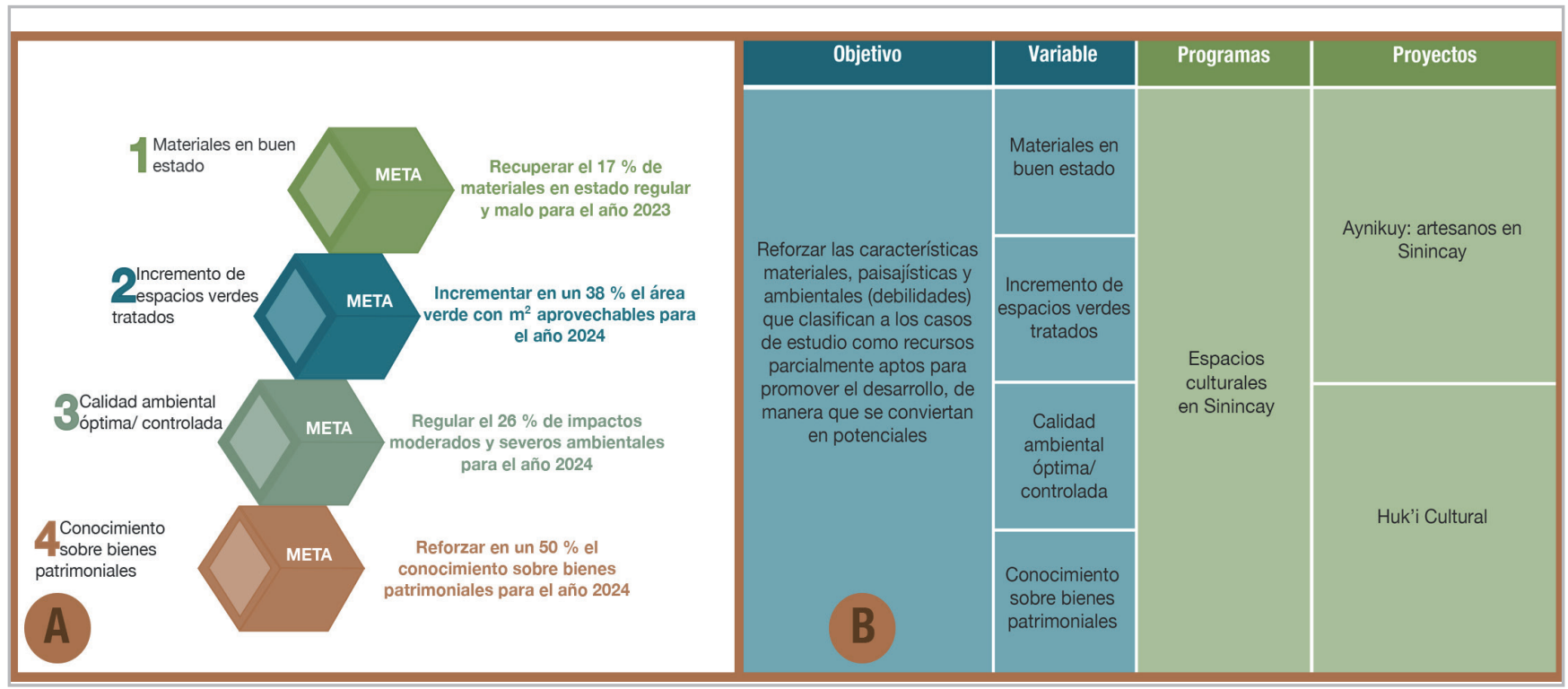

Figura 12.- (A) Metas establecidas para el año 2020. (B) Programas y proyectos propuestos. Fuente: García Cordero 2020. Elaboración: Autor. 


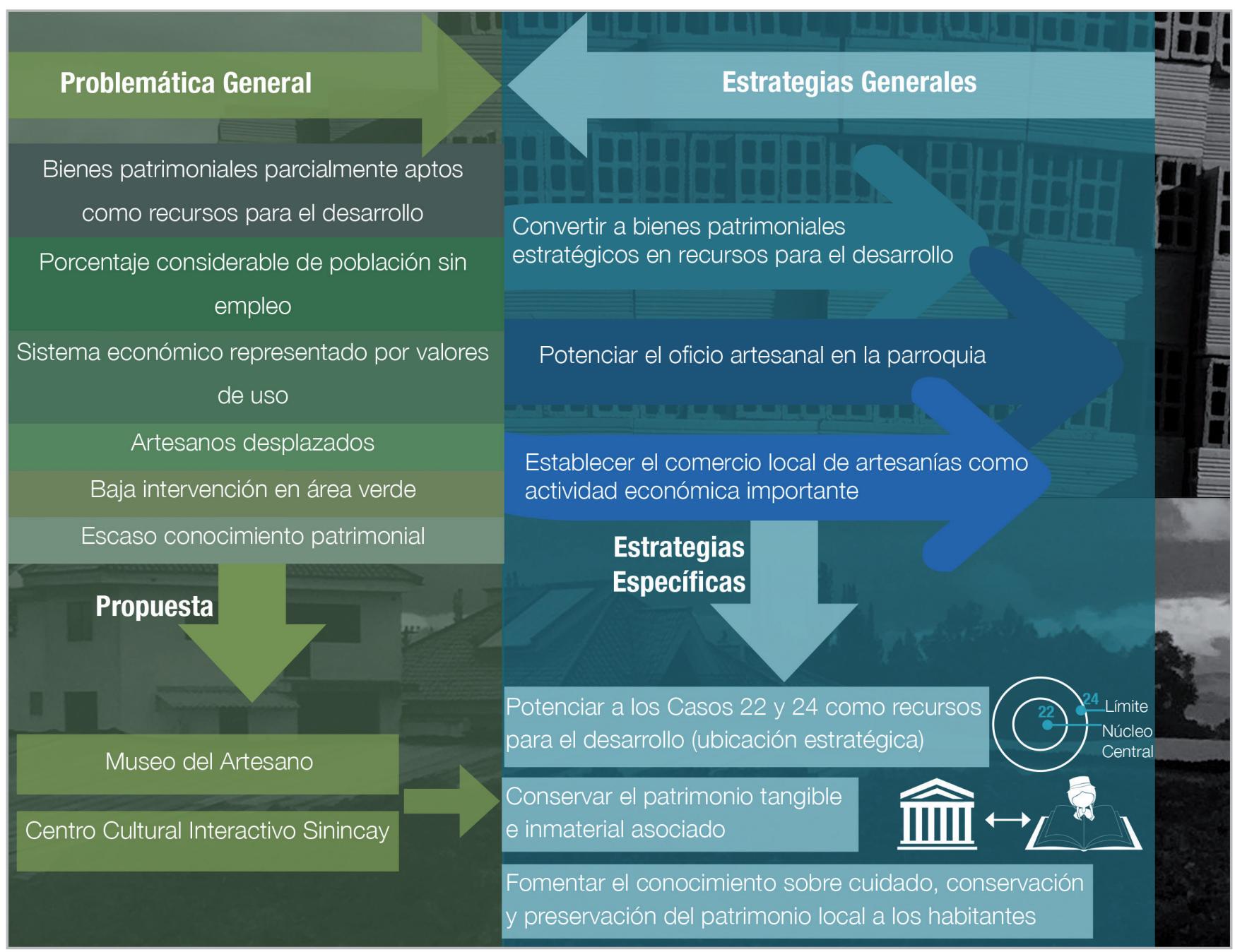

Figura 13.- Problemática y estrategias, generales y específicas. Fuente y elaboración: García Cordero 2020.

\section{Discusión}

Conforme los principios y visiones más contemporáneas, el reconocimiento del patrimonio vernáculo ha calado en amplios sectores de la sociedad hasta cultivar hábitos culturales que obligan a replantear las acciones y posiciones frente a él y a otros bienes del patrimonio cultural, cuyas lógicas no se corresponden con las categorías canónicas y sus prácticas frecuentes. Como es evidente, existen disfunciones, desencuentros y contraposiciones sobre el tema, pero no obstante, la aproximación amplía el patrimonio, ya sea vernáculo o en general, permite su introspección y prospección objetiva y coherente.

Como proceso histórico necesario, al analizar la legislación ecuatoriana vinculada con el patrimonio se pueden evidenciar posiciones. ¿Conoce la gente el valor de patrimonio?, ¿conoce la gente qué cuidados requiere el patrimonio?, ¿conoce la gente a las instituciones que salvaguardan el patrimonio y sus funciones? La normativa no siempre existe ni es aplicada ni socializada, ¿cómo entonces se puede aplicar algo que no se conoce? Además de socializarse y difundirse, la normativa debe ser inclusiva y permitir así ser aplicada tanto por la ciudadanía como por las distintas administraciones públicas. En este sentido, la introducción al empoderamiento del patrimonio cultural debe darse desde temprana edad para concientizar a las personas y brindarles herramientas para que sean capaces de aprender a conservarlo con el paso del tiempo. Buscar la correcta aplicación normativa y conservación objetiva se incluyen como horizontes deseables.

Sensibilizar y educar a la población fortalece el sentido de pertenencia, que también es imprescindible para el cuidado del patrimonio. Si el bien no se siente propio, no se cuida, se desgasta, lo que da como resultado edificios vacíos que se pierden con el tiempo. La opinión social frente al patrimonio se convierte en una variable que normalmente no se aplica, sin embargo, es capaz de representar un factor importante frente a posibles escenarios de riesgo (Turbay Varona, Ortiz, Arana y Ortiz 2020: 268) de deterioro o pérdida. A su vez, la falta de aplicación de leyes y normativas impide que el patrimonio ecuatoriano en general, y no solo el de Sinincay, cumpla con la función de agente para el progreso. Si este concepto se aplicara oportunamente, aportaría a la conservación del bien patrimonial, así como a la creación de beneficios para el asentamiento. 
Deotrolado,losproblemaspresentesenelámbitopatrimonial tienen a su vez relación directa con la planificación del territorio que lo abarca. Y, si bien se han creado programas, proyectos y políticas, que han transformado poco a poco la conciencia patrimonial, al igual que el cuidado y conservación de los bienes asociados, todavía existe inequidad en la periferia y ruralidad donde el cuidado no es del todo visible, por lo que es necesario generar conciencia y erradicarla. En este sentido, a pesar de los problemas a los que se ha enfrentado la ruralidad, el caso de Sinincay y su arquitectura muestran evolución y crecimiento, junto a los procesos y cambios a los que han estado expuestos a lo largo de los años. Caniggia y Maffei (1995) expresan que la comparación es una herramienta imprescindible en cualquier disciplina, a través de ella cualquier objeto adquiere su identidad y pasa a ser distinguible de los demás, aun si pertenece a una misma especie o grupo; sin embargo, los objetos o circunstancias que se van a analizar deben encontrarse en distintos espacios geográficos para no perder la posibilidad de reforzar el rasgo cultural que los caracteriza o los diferencia. Por ello, a lo largo del análisis se identificó la morfotipología en distintos sectores rurales de la provincia del Azuay en el siglo XX y la variación en el número de pisos y la relación lleno-vacío genera contraste significativo; asimismo, se puede observar muy marcado el uso del portal en las edificaciones rurales azuayas, por lo que se convierte en un elemento imprescindible. Se demuestra la réplica como una secuencia de distinciones temporales y espaciales, consecuencia de un proceso histórico que determina similitudes del tipo (Caniggia y Maffei 1995: 32).

Por otra parte, el potencial del patrimonio arquitectónico en Sinincay como recurso para el desarrollo se determina a partir de la comprensión de los cambios que se han generado en cuanto a forma y función frente a la relación con el medio que los rodea. Los nuevos valores que se le otorgan lo vuelven útil y productivo dentro de los paradigmas contemporáneos. Sin embargo, el peso de cada valor y los beneficios que este pueda producir se encuentran en constante cambio con notables pérdidas. De hecho, la dinámica que existe entre valores y beneficios es compleja y puede generar conflictos (Avrami y Mason 2019: 9).

En este contexto, si bien se considera que las principales actividades económicas de la parroquia se concentran en la ruralidad, las visitas en campo y comunicaciones personales con los habitantes muestran a la artesanía como una labor representativa del sector, pero a la que se le ha restado importancia. A su vez, a nivel del nacional y local se identifica que las herramientas y políticas generadas presentan incongruencias que deben aclararse y solucionarse (UNESCO, INPC y MCyP 2017: 50) con la visión de una articulación efectiva de la cultura en general y del patrimonio arquitectónico en particular en cuanto a los instrumentos de planificación territorial. El segmento de mayor sensibilidad es el patrimonio cultural inmaterial ( $\mathrm{PCl}$ ), el cual se presenta ampliamente desatendido.

Como estrategia emergente, la gestión de indicadores de integración que ofrece esta investigación propone una primera entrada: la inclusión de criterios de desarrollo (valor patrimonial, valor paisajístico), en la recuperación física del patrimonio arquitectónico de Sinincay.

\section{Conclusiones}

El análisis morfotipológico muestra que las características funcionales, constructivas y morfológicas de los bienes son similares por pertenecer a la misma época constructiva, localizarse en el mismo contexto o asociarse a la misma dinámica histórica. Estos hechos permiten aplicar los procedimientos de investigación en cualquier bien patrimonial de Sinincay para ampliar el estudio.

Por otro lado, la aplicación de las fichas urbanoarquitectónicas y las matrices de los estudios ambientales permite conocer que, sibien ninguno de los materiales, y por tanto de los edificios, han sido afectados de manera crítica, el $92 \%$ de ellos presentan alteraciones en nivel moderado y severo, lo que quiere decir que si los daños existentes no son mitigados y controlados puede ocasionarse la pérdida de uno o varios elementos arquitectónicos e incluso del inmueble en su totalidad. Todos los escenarios de pérdida suponen afecciones a la identidad de la localidad, por lo que la necesidad de intervención es inminente, tanto como el empoderamiento ciudadano para promoverla.

De los veinte factores impactantes considerados para el estudio, la falta de uso es uno de los que presenta mayor incidencia, ya que varios bienes inmuebles no tienen contacto frecuente con el usuario, por lo que se omiten acciones de cuidado básico y los bienes de manera innecesaria llegan a la incuria. También es de considerar que la falta de uso se asocia al abandono y a problemáticas sociales como la migración como parte de las determinantes de conservación típicas de otros asentamientos rurales y periurbanos. Estos, si bien han afectado al sitio, pueden ofrecer escenarios de mejora, conforme a las políticas y acciones internacionales y nacionales, asociadas y aplicables. Así, al analizar el potencial que poseen los bienes como recurso para el desarrollo, se determina que el patrimonio se muestra como un mecanismo para ello. Si bien es necesario reforzar y estudiar los parámetros correspondientes a campos externos a la arquitectura, como el ámbito económico, el $62 \%$ de los casos estudiados son aptos como recurso de desarrollo, mientras el $38 \%$ puede potenciarse. Es decir, existe un capital significativo.

\section{Referencias}

AGUIRRE ULLAURI, M. et al. (2017). "Evaluación del impacto ambiental en la arquitectura patrimonial a través de la aplicación de la Matriz de Leopold como un posible sistema de monitoreo interdisciplinar", ASRI: Arte y sociedad. Revista de investigación, 14, 14, 22-32. https://dialnet.unirioja.es/servlet/ articulo? codigo $=6266256$. 
AMAYA, S. (2006). "La Arquitectura vernácula en el ámbito de las convenciones internacionales sobre patrimonio cultural. Su potencial como Patrimonio de la Humanidad", La arquitectura vernácula, patrimonio de la humanidad. En Galindo, J. (Coord.). Badajoz: Colección Raíces. Asociación por la Arquitectura Rural Tradicional de Extremadura y Diputación Provincial, 49-52.

ANDRADE, S. (2016). "La construcción del discurso sobre patrimonio intangible y las políticas culturales en Ecuador", Boletín de Antropología, 31, 52: 221-247. https://doi.org/10.17533/udea. boan.v31n52a14.

ARÉVALO, J. M. (2004). "La tradición, el patrimonio y la identidad", Revista de estudios extremeños, 60 (3): 925-956. http://sgpwe.izt.uam. $\mathrm{mx} /$ files/users/uami/mcheca/GEOPATRIMONIO/LECTURA2E.pdf.

AVRAMI, E.; MASON, R. (2019). "Mapping the Issue of Values". En Values in Heritage Management, Avrami, E. et al. (eds.) Los Angeles: Getty Conservation Institute, 9-35.

AYALA MORA, E. (2008). "Época Republicana”, en Ortega, J. y Sigüenza, G. (eds.). Resumen de Historia del Ecuador. Quito: Corporación Editora Nacional, 26-44.

AYUNTAMIENTO DE MÁLAGA; OMAU. (2011) Agenda Málaga. Indicadores de Sostenibilidad. https://repositorio.uasb.edu.ec/ bitstream/10644/836/1/AYALAE-CON0001-RESUMEN.pdf

BANCO INTERAMERICANO DE DESARROLLO (BID) (2016). "Guía Metodológica Programa de Ciudades Emergentes y Sostenibles", https://n9.cl/fr84d.

BONFIL BATALLA, G. (2004). "Pensar nuestra cultura”, en Antología sobre cultura popular e indígena. Lecturas del Seminario Diálogos en la Acción, Primera Etapa, Dirección General de Culturas Populares (ed.) Ciudad de México, 117-134. Consejo Nacional para la Cultura y las Artes. Dirección General de Culturas Populares Indígenas. http://observatoriocultural.udgvirtual.udg.mx/repositorio/ handle/123456789/120?show=full.

BORRERO, A. L. (2006). "Cambios históricos en el paisaje de Cuenca, siglos XIX-XX", Procesos, 24: 108-134. http://hdl.handle. $\underline{\text { net/10644/1785 }}$

CAMBÓN, E. del C. (2009). "Paisajes Culturales como Patrimonio: criterios para su identificación y evaluación", Arquitectura y Urbanismo, 30 (1): 10-17. http://rau.cujae.edu.cu/index.php/ revistaau/article/view/79/78

CANADIAN CONSERVATION INSTITUTE e ICCROM (2016). The $A B C$ Method: a risk management approach to the preservation of cultural heritage. Ottawa: Canadian Conservation Institute. https:// n9.cl/95h6m.

CANIGGIA, G.; MAFFEI, G. L. (1995). Acústica de la edificación. Madrid: Celeste Ediciones. https://dialnet.unirioja.es/servlet/ articulo?codigo $=6266260$

CARDOSO ARÉVALO, K. (2017). "Análisis comparativo de inventarios fotográficos. El uso de la información y la fotografíaa histórica en la gestión y conservación del Patrimonio", Arte y Sociedad. Revista de investiación, 14: 79-94.

CARRIÓN, F. (1986). El proceso de urbanización en el Ecuador (del siglo XVIII al siglo XX). Quito: Centro de Investigaciones Ciudad.

CHUECA GOITA, F. (1981). “Invariantes Castizos de la Arquitectura Española, Invariantes en la Arquitectura Hispanoamericana, Manifiesto de la Alhambra". Editorial Dossat.

CORIA, D. I. (2008). "El estudio de impacto ambiental: características y metodologías", Invenio, 20(11): 125-135. http:// www.redalyc.org/articulo.oa?id=87702010

CORTÉS AGUIRRE, A., AGUIRRE ULLAURI, M. del C.; CONTRERAS ESCANDÓN, C. (2019). "Impacto del Decreto de Emergencia del Patrimonio Cultural del Ecuador: análisis costo-beneficio", Revista de Urbanismo, 41: 1-20. https://doi.org/10.17533/udea.boan.v31 n52a1410.5354/0717-5051.2019.52492.

ESCOBAR, J.; BONILLA JIMÉNEZ, I. (2009). “Grupos Focales : una guía conceptual y metodológica", Cuadernos Hispanoamericanos de Psicología, 9(1): 51-67. http://www.tutoria.unam.mx/sitetutoria/ayuda/gfocal-03122015.pdf.

GÁMEZ, V. (2008). Patrimonio en la periferia: Enclaves Patrimoniales y Marcas de identidad local en el ordenamiento territorial del Gran Santiago. Sevilla: Universidad de Sevilla. https://n9.cl/b2ixt.

GARCÍA CORDERO, A. P. (2020). Análisis Morfotipológico de la arquitectura patrimonial periférica en Cuenca. El caso de Sinincay. Cuenca: Universidad Católica de Cuenca.

GARCÍA, G., TAMAYO, J., COBO, D.; CORONEL, F. I. (2017). «Estudio tipológico de la arquitectura vernácula. Aportes y síntesis de la complejidad». ASRI-Arte y Sociedad. Revista de Investigación, 14: 295-311. https://dialnet.unirioja.es/servlet/ articulo?codigo $=6266274$

GOBIERNO AUTÓNOMO DESCENTRALIZADO DEL CANTÓN CUENCA (GAD del Cantón Cuenca) (2015). “Plan de Desarrollo y Ordenamiento Territorial del Cantón Cuenca. Actualización 2015", Cuenca: Ilustre Municipalidad de Cuenca. http://www.cuenca. gob.ec/?q=system/files/PDOT 2016 editado $0 . p d f$

GOBIERNO AUTÓNOMO DESCENTRALIZADO DEL CANTÓN CUENCA (GAD de la parroquia Sinincay. (2015). "Actualización del Plan de Desarrollo y Ordenamiento Territorial de la parroquia Sinincay", Cuenca: GAD Sinincay.

HERMIDA, M. A. et al. (2015). "La densidad urbana como variable de análisis de la ciudad. El caso de Cuenca, Ecuador", Eure 124 (41): 25-44. https://n9.cl/95t6g.

HERMIDA, M. A.; MOGROVEJO, V. (2011). Valores formales de la vivienda rural tradicional del Siglo XX en la Provincia del Azuay. Cuenca: Universidad de Cuenca. https://doi.org/10.13140/ RG.2.2.27864.90884. 
ICOMOS (1967). Informe final de la reunión sobre conservación y utilización de monumentos y lugares de interés histórico y artístico. Quito. https://www.icomos.org/charters/quito.htm.

ICOMOS (1999). "Carta del patrimonio vernáculo construido (1999)", Carta do Património Vernáculo Construido. México: ICOMOS, 1-3. https://www.icomos.org/images/DOCUMENTS/Charters/ vernacular sp.pdf.

Instituto Nacional de Patrimonio Cultural -INPC- (2012). "Guía Didáctica para mantenimiento y conservación de Bienes Inmuebles Patrimoniales", https://issuu.com/riesgosinpc/docs/guia didactiva conseravcion bienes inmuebles.

Instituto Nacional de Patrimonio Cultural -INPC- (2019). Ecuador cuenta con nuevas normativas técnicas para la gestión del patrimonio inmuebley subacuático. Quito. https://n9.cl/jgko8.

JAMIESON, R. W. (2003). De Tomebamba a Cuenca. Quito: Abya-Yala. http://digitalrepository.unm.edu/cgi/viewcontent. cgi?article $=1090 \&$ context=abya yala.

KENNEDY TROYA, A. (2016). Élites y la nación en Obras. Visualidades y arquitectura del Ecuador 1840-1930. Cuenca: Universidad de Cuenca.

LÓPEZ ULLOA, S. (2004). "Ecuador Legislación Patrimonial", Areté Documenta, V Patrim: 57-64. http://oa.upm.es/629

MANNONI, T.; GIANNICHEDDA, E. (2004). Arqueología de la producción. Barcelona: Ariel.

MARTíNEZ DALMAU, R. (2017). "Constitucionalismo democrático e innovación constitucional en Ecuador: la Constitución de 2008, Diálogos de saberes, 47: 1-24. https://doi.org/10.18041/0124-0021/ dialogos.47.1589.

MEJÍA, Á. R. (2014). "El patrimonio cultural como derecho: el caso ecuatoriano", Revista de Derecho, 21: 5-26. https://revistas.uasb.edu. ec/index.php/foro/article/view/430.

MINISTERIO DE CULTURA Y PATRIMONIO -MCyP-. (2014). "Proyecto Emblemático Ciudades Patrimoniales del Ecuador". Quito. https:// n9.cl/5hsth.

MUÑOZ, P. (2015). Arquitectura popular en Azuay y Cañar 19771978: cuadernos de trabajo de Patricio Muñoz Vega y compilación gráfica. Cuenca: CIDAP, Universidad de Cuenca.

PÁEZ BARRERA, O. (2011). "Ver lo mismo, pero con otros ojos: iconografía arquitectónica de la Cuenca Histórica", Revista Pucará, 23 (483): 211-212. https://docplayer.es/ docview/79/79687586/\#file=/storage/79/79687586/79687586. pdf

PARENTI, R. (1995). Historia, importancia y aplicaciones del método de lectura de paramentos. Informes de la Construcción, 435 (46): 19-29. https://doi.org/10.3989/ic.1995.v46.i435.1094.

RAPOPORT, A. (1965). The meaning of the built environment: a nonverbal communication, The British Journal of Psychiatry. Tucson: The University of Arizona Press. https://doi.org/10.1192/ bjp.111.479.1009-a.

SANDOVAL, L. K. (2017). "Patrimonio cultural y turismo en el Ecuador: Vínculo indisoluble", Revista de investigación Científica, 9: 1-24. https://doi.org/10.29019/tsafiqui.v0i9.349.

TERÁN, C. (1947). "Índice Histórico de la Diócesis de Cuenca. 1919-1944". Cuenca: Editorial Católica.

TERÁN, F. (1970) "Reflexiones sobre la crisis del planeamiento", Ciudad y territorio, estudios territoriales, 3: 11-30. Disponible en: http://oa.upm.es/11045/

TURBAY VARONA, I. et al. (2020). “La incidencia de la opinión social en el grado de vulnerabilidad de los edificios patrimoniales. El caso del centro histórico de Popayán (Colombia)", Ge-conservación, 17: 267-279. https://doi.org/10.37558/gec.v17i1.777.

UNESCO, INPC y MCyP. (2017). Aporte para la consolidación de la Política Pública sobre el Patrimonio Cultural Inmaterial del Ecuador Proyecto. Quito: UNESCO.

ZAMBRANO, A; LEÓN, M. (1993). Análisis de la evolución de la arquitectura rural. Casos Checa, Chiquintad y Sinincay. Cuenca: Universidad de Cuenca.

ZAMORA, E. (2011)."Sobre patrimonio y desarrollo. Aproximación al concepto de patrimonio cultural y su utilización en procesos de desarrollo territorial". Pasos. Revista de Turismo y Patrimonio Cultural, 9(1): 101-115. http://www.pasosonline.org/ Publicados/7309special/PASOS18.pdf\#page $=47$.

\section{Autor/es}

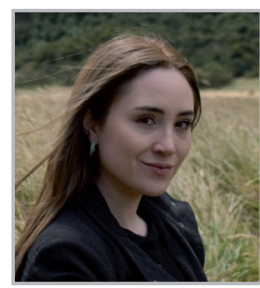

Amanda Paulina García Cordero apgarciac10@gmail.com Universidad Católica de Cuenca (UCACUE), Ecuador https://orcid.org/0000-0002-4729-9850.

Arquitecta por la Universidad Católica de Cuenca. Colaboradora en la Organización Nacional de Estudiantes de Arquitectura -ONEA- (Noviembre 2015 - Agosto 2016).Participante en el proyecto de investigación académica "Los materiales en el estudio histórico-constructivo-ambiental de los conjuntos históricos. El caso de Cuenca".

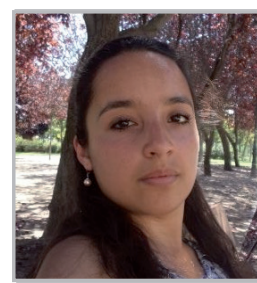

María del Cisne Aguirre Ullauri

maguirreu@ucacue.edu.ec

Universidad Católica de Cuenca (UCACUE) Ecuador

http://orcid.org/0000-0002-3179-7839

Arquitecta, Máster Universitario en Conservación y Restauración del Patrimonio Arquitectónico. Estudiante del Programa de 
Doctorado en Patrimonio Arquitectónico por la Universidad Politécnica de Madrid (España). Docente Titular y Coordinadora del Centro de Investigación de Ingeniería, Industria, Construcción y TIC de la Universidad Católica de Cuenca (Ecuador). Miembro de los Grupo d Investigación CAT -Ciudad, Ambiente y Tecnologíay Ciencia \& Diversidad de la Universidad Católica de Cuenca, la Red Ecuatoriana de Mujeres Científicas, ICOMOS Internacional y la Organization for Women in Science for the Developing World.

Artículo enviado el 26/11/2020

Artículo aceptado el 04/06/2021

(c) (1) $(9)$

https://doi.org/10.37558/gec.v20i.868 